\title{
Review \\ Radiolabeled Somatostatin Analogues for Diagnosis and Treatment of Neuroendocrine Tumors
}

\author{
Valentina Ambrosini ${ }^{1,2}$, Lucia Zanoni ${ }^{2, *}$, Angelina Filice ${ }^{3}$, Giuseppe Lamberti ${ }^{1,4}$, Giulia Argalia ${ }^{1}(\mathbb{D}$, \\ Emilia Fortunati ${ }^{1}$, Davide Campana ${ }^{1,4}$ (D) Annibale Versari ${ }^{3}$ and Stefano Fanti ${ }^{1,2}$ (D)
}

1 Department of Experimental Diagnostic and Specialized Medicine, University of Bologna, 40138 Bologna, Italy; valentina.ambrosini@unibo.it (V.A.); giuseppe.lamberti8@unibo.it (G.L.); giulia.argalia@studio.unibo.it (G.A.); emilia.fortunati@studio.unibo.it (E.F.); davide.campana@unibo.it (D.C.); stefano.fanti@aosp.bo.it (S.F.)

2 Nuclear Medicine Unit, IRCCS Azienda Ospedaliero-Universitaria di Bologna, 40138 Bologna, Italy

3 Nuclear Medicine Unit, Azienda USL-IRCCS di Reggio Emilia, 42123 Reggio Emilia, Italy; angelina.filice@ausl.re.it (A.F.); annibale.versari@asmn.re.it (A.V.)

4 Division of Medical Oncology, IRCCS Azienda Ospedaliero-Universitaria di Bologna, 40138 Bologna, Italy

* Correspondence: lucia.zanoni@aosp.bo.it

check for updates

Citation: Ambrosini, V.; Zanoni, L.; Filice, A.; Lamberti, G.; Argalia, G.; Fortunati, E.; Campana, D.; Versari,

A.; Fanti, S. Radiolabeled

Somatostatin Analogues for

Diagnosis and Treatment of

Neuroendocrine Tumors. Cancers

2022, 14, 1055. https://doi.org/

10.3390/cancers14041055

Academic Editor: Elif Hindié

Received: 31 December 2021

Accepted: 17 February 2022

Published: 19 February 2022

Publisher's Note: MDPI stays neutral with regard to jurisdictional claims in published maps and institutional affiliations.

Copyright: (C) 2022 by the authors. Licensee MDPI, Basel, Switzerland. This article is an open access article distributed under the terms and conditions of the Creative Commons Attribution (CC BY) license (https:// creativecommons.org/licenses/by/ $4.0 /)$.
Simple Summary: Neuroendocrine neoplasms (NENs) are rare and heterogeneous tumors, presenting in often challenging clinical scenarios, and require multidisciplinary discussion for optimal care. The theranostic approach (DOTA peptides labelled with ${ }^{68} \mathrm{Ga}$ for imaging well-differentiated neuroendocrine tumors NETs, and labelled with ${ }^{90} \mathrm{Y}$ or ${ }^{177} \mathrm{Lu}$ for therapy) plays a crucial role in the management of NENs to assess disease extension and criteria for peptide receptor radionuclide therapy (PRRT) eligibility of based on somatostatin receptor (SSTR) expression. The present paper is an overview of currently employed radiolabeled SSTR analogues used for both diagnosis and therapy of NENs. Further emerging radiopharmaceuticals targeting SSTRs (e.g., fluorinated SSTR agonists, radiolabeled SSTR antagonists) as well as strategies to improve PRRT efficacy (by means of implementation of personalized treatment schemes, dosimetry, amelioration of response assessment strategies, and optimization of treatment sequencing) are also discussed. Finally, although very preliminary, some studies employing radiomic features in various kinds of NET are reported.

\begin{abstract}
Neuroendocrine neoplasms (NENs) are rare and heterogeneous tumors that require multidisciplinary discussion for optimal care. The theranostic approach (DOTA peptides labelled with ${ }^{68} \mathrm{Ga}$ for diagnosis and with ${ }^{90} \mathrm{Y}$ or ${ }^{177} \mathrm{Lu}$ for therapy) plays a crucial role in the management of NENs to assess disease extension and as a criteria for peptide receptor radionuclide therapy (PRRT) eligibility based on somatostatin receptor (SSTR) expression. On the diagnostic side, [ $\left.{ }^{68} \mathrm{Ga}\right] \mathrm{Ga}$-DOTA peptides PET/CT (SSTR PET/CT) is the gold standard for imaging well-differentiated SSTR-expressing neuroendocrine tumors (NETs). $\left[{ }^{18}\right.$ F]FDG PET/CT is useful in higher grade NENs (NET G2 with Ki-67 > 10\% and NET G3; NEC) for more accurate disease characterization and prognostication. Promising emerging radiopharmaceuticals include somatostatin analogues labelled with ${ }^{18} \mathrm{~F}$ (to overcome the limits imposed by ${ }^{68} \mathrm{Ga}$ ), and SSTR antagonists (for both diagnosis and therapy). On the therapeutic side, the evidence gathered over the past two decades indicates that PRRT is to be considered as an effective and safe treatment option for SSTR-expressing NETs, and is currently included in the therapeutic algorithms of the main scientific societies. The positioning of PRRT in the treatment sequence, as well as treatment personalization (e.g., tailored dosimetry, re-treatment, selection criteria, and combination with other alternative treatment options), is warranted in order to improve its efficacy while reducing toxicity. Although very preliminary (being mostly hampered by lack of methodological standardization, especially regarding feature selection/extraction) and often including small patient cohorts, radiomic studies in NETs are also presented. To date, the implementation of radiomics in clinical practice is still unclear. The purpose of this review is to offer an overview of radiolabeled SSTR analogues for theranostic use in NENs.
\end{abstract}


Keywords: somatostatin; neuroendocrine; [Ga]-DOTA peptides PET/TC; PRRT

\section{Introduction}

Neuroendocrine neoplasms (NENs) account for $0.5 \%$ of all malignancies; they are rare, heterogeneous (in terms of primary tumor site, behavior over time, and differentiation grade), and mostly slow-growing and non-functioning, originating from the secretory cells of the neuroendocrine system, and widely dispersed in the human body. The majority of NENs $(72 \%)$ arise from the gastroenteropancreatic (GEP) tract, followed by the bronchopulmonary system $(25 \%)$, while other primary sites are less frequent (e.g., adrenals, thyroid, breast, prostate, skin). A minority of cases present as inherited syndromes (e.g., von Hippel-Lindau disease (VHL), multiple endocrine neoplasia (MEN), neurofibromatosis, tuberous sclerosis). NENs are pathologically classified depending on cells' morphology and differentiation (Ki-67 and the mitotic count) into well-differentiated tumors (NETs) (graded as NET G1: Ki-67 < 3\% or mitotic count per 10 high-power fields < 2; NET G2: Ki-67 with 3-20\% or 2-20 mitoses; NET G3 Ki- $67>20 \%$ or $>20$ mitoses) [1,2] and poorly differentiated neuroendocrine carcinoma (NEC, Ki-67 > 20\%).

The diagnostic workup of NENs is challenging, mostly because they often present as small lesions with variable anatomical localization.

Conventional imaging (CI) procedures (e.g., ultrasound (US), diagnostic computed tomography (dCT), magnetic resonance imaging (MRI)) are routinely employed [3-5] for imaging of NENs; the sensitivity and detection rate of dCT are suboptimal (NET disease: sensitivity range (61-93\%) and specificity range (71-100\%); liver metastases: sensitivity range (75-100\%) and specificity (83-100\%); nodes: sensitivity range (60-70\%) and specificity $(87-100 \%)$ ) [6-8]. For imaging of the abdomen, bone, and brain, MRI is generally better than dCT. Endoscopic US is the most sensitive method for diagnosing pancreatic NETs $($ mean sensitivity $=86 \%(82-93 \%)$; mean specificity $=92 \%(86-95 \%)$ ), and CEUS may be considered for localization of NET liver metastases and pancreatic NETs $[6,8]$.

The diagnostic workup of NENs was therefore revolutionized by the introduction of nuclear medical procedures able to detect the presence of somatostatin receptors (SSTRs), which are typically overexpressed in well-differentiated NEN cells.

Over the years, several studies have indicated that SSTR PET/CT (positron emission tomography) imaging is superior to SSTR scintigraphy or conventional anatomic imaging (US, dCT, or MRI) for the assessment of well-differentiated NETs. For example, SSTR PET/CT can locate the primary tumor site, and often demonstrates additional lesions not captured by conventional imaging, resulting in more accurate evaluation of disease extension, followed by relevant changes in management in approximately one-third of patients $[9,10]$.

Furthermore, SSTR agonists (e.g., DOTA-TOC, DOTA-NOC, DOTA-TATE) currently used for PET/CT imaging allow not only the evaluation of disease extension when labelled with ${ }^{68} \mathrm{Ga}$, but also the selection of candidate patients for target therapy with either nonradioactive or radioactive ([$\left.{ }^{90} \mathrm{Y}\right] \mathrm{Y}$-DOTA-TOC or $\left[{ }^{177} \mathrm{Lu}\right] \mathrm{Lu}$-DOTATATE) somatostatin analogues.

The present paper discusses currently clinically employed radiopharmaceuticalsagonists of the SSTR-for both diagnosis and therapy of NENs.

\section{Imaging of NENs with Radiolabeled Somatostatin Analogues}

SSTR expression can be demonstrated in vivo by radiolabeled somatostatin analogues using planar scintigraphy, single-photon-emission computed tomography (SPECT)/CT, or $\mathrm{PET} / \mathrm{CT}$, the latter being the imaging modality of choice when available.

In fact, the first agent to obtain Food and Drug Administration (FDA) approval in 1994 for planar and SPECT imaging was [ $\left.{ }^{111} \mathrm{In}\right] \mathrm{In}$-pentetreotide (Octreoscan ${ }^{\mathrm{TM}}$ ); it was, however, characterized by less favorable dosimetry and lower diagnostic performance (detection 
rate ranging between $50 \%$ and $100 \%$ [6-8]) when compared with $\left[{ }^{68} \mathrm{Ga}\right.$-DOTA peptides ([ $\left.{ }^{68} \mathrm{Ga}\right] \mathrm{Ga}-\mathrm{DOTA}-\mathrm{TOC},\left[{ }^{68} \mathrm{Ga}\right] \mathrm{Ga}$-DOTA-NOC, $\left.\left[{ }^{68} \mathrm{Ga}\right] \mathrm{Ga}-\mathrm{DOTA}-\mathrm{TATE}\right)$, mostly due to the suboptimal physical characteristics of the radiopharmaceutical, high physiological liver uptake (frequent site of NET metastases), gamma camera's lower spatial resolution, and increased patient discomfort due to later/longer acquisition times for imaging [9].

Since its first introduction in clinical practice, SSTR PET/CT has demonstrated several advantages over scintigraphic imaging (i.e., higher spatial resolution, more favorable biodistribution at liver/bowel level, semi-quantitative analysis), and currently represents the gold standard functional imaging modality for NETs, and is recommended by all guidelines [6,8].

The radiopharmaceuticals currently used for SSTR PET/CT present a common structure: a positron-emitting isotope $\left({ }^{68} \mathrm{Gallium},{ }^{68} \mathrm{Ga}\right)$, a chelant (DOTA), and the SSTR ligand (NOC, TOC, TATE). This corresponds to three clinically employed tracers- $\left[{ }^{68} \mathrm{Ga}\right] \mathrm{Ga}-$

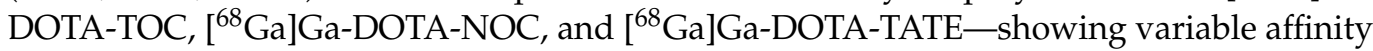
for the SSTR subtypes.

${ }^{68} \mathrm{Ga}$ is a positron-emitting radionuclide that can only be applied for diagnostic imaging; its short half-life ( $68 \mathrm{~min}$ ) makes it unsuitable for dosimetry, and therefore inapplicable for therapeutic purposes. Different types of ${ }^{68} \mathrm{Ge} /{ }^{68} \mathrm{Ga}$ generators are currently available with marketing authorization and using kit-based radiolabeling. The radiopeptides function as receptor agonists to SSTR through the activation and internalization of the receptor upon binding. Despite different SSTR subtypes' affinities, the clinical performance of the available radiopharmaceuticals is considered clinically comparable, since they all bind with high affinity to SSTR-2 - the subtype predominantly expressed in most NENs.

$\left[{ }^{68} \mathrm{Ga}\right] \mathrm{Ga}-\mathrm{DOTA}-\mathrm{TOC}$ was the first PET SSTR ligand, developed in 2001 and approved in Europe in 2016, and by the FDA in 2019 [11]; it has an octreotide-like SSTR affinity profile-indeed, it has affinity for SSTR-2 and -5 , but lower compared to the [ $\left.{ }^{68} \mathrm{Ga}\right] \mathrm{Ga}$ DOTA-NOC. SSTR-2 expression in immunohistochemistry demonstrated a significant correlation with the standardized uptake value (SUV) [12]. DOTATOC can also be labelled with ${ }^{90} \mathrm{Y}$ for theranostic applications.

$\left[{ }^{68} \mathrm{Ga}\right] \mathrm{Ga}-\mathrm{DOTA}-$ lanreotide ([68Ga]Ga-DOTA-LAN) binds to SSTR-2 and -5 [13].

$\left[{ }^{68} \mathrm{Ga}\right] \mathrm{Ga}-\mathrm{DOTA}-\mathrm{NOC}$ has high affinity for SSTR-2,3,5 [14].

$\left[{ }^{68} \mathrm{Ga}\right] \mathrm{Ga}-D O T A-T A T E$, which received FDA approval in 2016 (https: / / www.accessdata. fda.gov /drugsatfda_docs/label/2018/208547s011lbl.pdf accessed on 6 November 2021), shows the highest affinity for SSTR-2, with a higher tumor-to-background ratio (TBR) compared to [ ${ }^{68} \mathrm{Ga}$ ]Ga-DOTA-NOC [15]; moreover, when labelled with ${ }^{177} \mathrm{Lu}$, it can be employed for NET peptide receptor radionuclide therapy (PRRT), approved by the EMA in 2017 and by the FDA in 2018 (https: / / www.accessdata.fda.gov/drugsatfda_docs/label/20 18/208700s000lbl.pdf accessed on 6 November 2021). For diagnostic purposes, DOTATATE was also labelled with ${ }^{64} \mathrm{Cu}$ [16]; such labelling offers a longer radionuclide half-life (12.7 h of ${ }^{64} \mathrm{Cu}$ vs. $68 \mathrm{~min}$ of ${ }^{68} \mathrm{Ga}$ ), shorter positron range in tissue (mean $0.6 \mathrm{vs} .3 .5 \mathrm{~mm}$ ), and lower positron branching ratio $(0.17$ vs. 0.89$)$, resulting in higher TBR at delayed images (acquired 3-24 h p.i.). [ ${ }^{64} \mathrm{Cu}$ ]Cu-DOTA-TATE received FDA approval in 2020 (https: / / www.accessdata.fda.gov/drugsatfda_docs/label/2020/213227s000lbl.pdf accessed on 6 November 2021).

\subsection{SSTR PET/CT Indications}

The procedural guidelines of the European Association of Nuclear Medicine (EANM) for the use of PET/CT imaging with $\left[{ }^{68} \mathrm{Ga}\right] \mathrm{Ga}-\mathrm{DOTA}-$ peptides were last updated in 2017 [14].

According to the 2017 EANM guidelines, SSTR PET /CT is recommended as the first choice to study patients with foregut and midgut NETs and head and neck paraganglioma; it is generally considered to be the second choice for abdominal paraganglioma (second to $\left[{ }^{18} \mathrm{~F}\right] \mathrm{F}-\mathrm{DOPA}$ ) and hindgut NETs (second to $\left.\left[{ }^{18} \mathrm{~F}\right] \mathrm{FDG}\right)$. Finally, SSTR PET/CT is indicated as the third choice for medullary thyroid carcinoma (MTC) [14]. 
EANM guidelines recommend SSTR PET/CT for:

- Detection of primary occult site (CUP) in patients with demonstrated neuroendocrine metastasis or with increased specific tumor markers, with negative conventional imaging for primary lesions;

- Characterization of bronchial masses with inconclusive conventional imaging;

- Characterization, staging, and restaging of foregut NETs;

- Characterization, staging, and restaging of midgut NETs when $\left[{ }^{18} \mathrm{~F}\right] \mathrm{F}-\mathrm{DOPA}$ was unavailable or inconclusive.

Regarding patient management, SSTR-PET/CT is indicated for:

- Staging/restaging of residual or recurrent disease;

- Prognosis (since SSTR-positive tumors are more likely to respond to targeted somatostatin analogue therapy);

- $\quad$ Assessment of eligibility for PRRT (with [177 Lu]Lu or [ $\left.{ }^{90} \mathrm{Y}\right] \mathrm{Y}$-DOTA-peptides);

- Therapy response monitoring (surgery, radiotherapy, chemotherapy, or PRRT).

Although a large body of literature is available on NENs, many systematic reviews and meta-analyses suggest that strong clinical evidence is often difficult to achieve, mostly due to the rarity, clinical heterogeneity, and lack of methodological standardization of imaging and clinical studies. In fact, the clinical management and diagnostic workup often varies between countries, influenced by both instrumental availability and reimbursement policies.

A step towards standardization was made in 2008, when the ENETS (European Neuroendocrine Tumor Society) set up an accreditation/certification program that allows participating centers to display the expertise of their multidisciplinary teams' knowledge of and adherence to ENETS guidelines for patient care, in order to increase patient-oriented care and participation in clinical trials, as well as collaboration between centers. Since 2009, 62 ENETS Centers of Excellence (CoEs) have been accredited worldwide [15].

In order to further define the appropriate use criteria (AUC, RAND/UCLA Appropriateness Method) for SSTR PET/CT, a pool of expert representatives of several societies (the Society of Nuclear Medicine and Molecular Imaging, the American College of Radiology, the American Society of Clinical Oncology, the North American Neuroendocrine Tumor Society, the European Association of Nuclear Medicine, the Endocrine Society, the Society of Surgical Oncology, the National Comprehensive Cancer Network, the American College of Physicians, the American Gastroenterological Association, and the World Conference on Interventional Oncology) gathered to rate 12 clinical scenarios [17]; 9 out of 12 were considered appropriate: initial staging after the histological diagnosis of NET; localization of a primary tumor in patients with known metastatic disease but an unknown primary; selection of patients for PRRT; staging of NETs prior to planned surgery; evaluation of a mass suggestive of an NET not amenable to endoscopic or percutaneous biopsy (e.g., ileal lesion, hypervascular pancreatic mass, mesenteric mass); monitoring of NETs seen predominantly on SSTR-PET; evaluation of patients with biochemical evidence and symptoms of an NET without evidence of it on CI, and without prior histological diagnosis of an NET; restaging at the time of clinical or laboratory progression without progression on CI; and new indeterminate lesion on $\mathrm{CI}$ with unclear progression.

More recently, a harmonization project was promoted by the EANM Focus 3 Consensus [18,19]; a multidisciplinary modified Delphi process (including 24 international experts) was applied to assess the most debated issues in the management of well-differentiated NETs, in order to reach a final consensus. SSTR PET/CT was recommended for unknown primary NETs, metastatic NETs, NET staging/restaging, suspected extra-adrenal pheochromocytoma/paraganglioma, and suspected paraganglioma.

\subsection{SSTR PET/CT Procedure}

SSTR PET/CT procedural guidelines were published by the EANM and ENETS in $2017[6,8,14]$. The recommended dose is between 100 and 200 MBq. Uptake time is slightly 
different between conjugated peptides: 45-60 min for TATE, and 60-90 min for TOC and NOC; there is no need for fasting.

A temporary withdrawal before PET examination of medications with "cold" somatostatin analogues is preferable (to avoid SSTR blockade), but not strictly necessary. In case of discontinuation, 1 day is recommended in the case of short-acting molecules, whereas $3-4$ weeks is recommended for long-acting molecules. The optimal timing would be to perform the scan just before the scheduled monthly dose of long-acting analogues [14].

Precautions should be taken in case of pregnancy and subjects $<18$ years (benefit vs. risk evaluation), as well as breastfeeding (interruption for 7 physical half-lives of the administered radionuclide).

\section{3. $\left[{ }^{68} \mathrm{Ga}\right] \mathrm{Ga}$-DOTA Peptides' Biodistribution and Pitfalls}

The maximum tumor activity was found at $70 \pm 20$ min post-injection (pi) [20]. Excretion was predominately via kidney. Physiological uptake was demonstrated in the liver, spleen (by far the site of highest uptake), pituitary, thyroid, and salivary glands (faint), kidneys, adrenal glands, stomach, bowel (linear, non-focal), prostate gland, and breast. Variable uptake was found in the pancreas; in particular, the expression of SSTR-2 was detected in the islets-especially in the pancreatic head. The pattern of uptake of the uncinate process / head of the pancreas can be focal or diffuse, and may present as higher than that of the liver. For definitive image interpretation, a negative $\mathrm{dCT}$ confirming the absence of a morphologically evident lesion is mandatory.

Although the liver is a frequent site of NENs' metastatic spread, the detection of lesions presenting an uptake higher than the liver is generally a positivity criterion for pathological SSTR expression.

Various false-negative findings were encountered, especially lesion de-differentiation, histotypes with absent or variable SSTR expression (e.g., medullary thyroid carcinoma, neuroblastoma, insulinoma, pheochromocytoma), small lesions (under PET/CT spatial resolution), and lesions at sites of physiological biodistribution (hampering tumor detectability).

False-positive findings were also frequent; SSTR increased expression of activated lymphocytes at sites of inflammation/infection, non-neuroendocrine tumors expressing SSTR (including breast, prostate, head and neck, renal cell, differentiated thyroid carcinoma, non-small-cell lung cancer, melanoma, lymphoma, sarcoma, and astrocytoma), accessory spleens (including intrapancreatic ones), and splenules [14].

\subsection{SSTR PET/CT Diagnostic Performance and Clinical Impact}

The data collected in the past decade certainly prove that nuclear medicine procedures have the highest accuracy for the detection of NET lesions, and strongly influence the patients' clinical management.

As previously mentioned, several studies have reported the higher diagnostic accuracy of SSTR PET/CT as compared to somatostatin receptor scintigraphy and CT [9,21,22].

Moreover, published data indicate that the results obtained with the currently available SSTR agonists are clinically equivalent (although semi-quantitative parameters' absolute values may differ when using different compounds, rendering absolute SUV values not directly comparable).

A large cohort study (728 patients with confirmed NET/suspected NET and different primary tumor sites; $1258 \mathrm{PET} / \mathrm{CT}$ scans) performed at a single institution reported that the diagnostic performance of SSTR PET /CT $\left(\left[{ }^{68} \mathrm{Ga}\right] \mathrm{Ga}\right.$-DOTA-TATE) was very high regardless of the primary tumor site or of the indications for PET/CT scanning (in particular, sensitivity, specificity, accuracy, positive predictive value, and negative predictive value were $97 \%, 95.1 \%, 96.6 \%, 98.5 \%$, and $90.4 \%$, respectively) [23]. 
The superiority of SSTR PET/CT as compared to CT was reported in particular for the detection of small lesions, as well as nodal and bone metastases [9,24,25]. A dramatic decrease in survival was in fact reported for patients with bone involvement on $\left[{ }^{68} \mathrm{Ga}\right] \mathrm{Ga}$-DOTA-TATE PET/CT; patients without signs of metastasis on $\left[{ }^{68} \mathrm{Ga}\right] \mathrm{Ga}-\mathrm{DOTA}-$ TATE PET/CT showed a longer overall survival (of $95.7 \%, 88.6 \%$, and $81.3 \%$ at 1, 3, and $5 \mathrm{y}$, respectively) compared with patients with soft-tissue metastasis $(90.5 \%, 82.3 \%$, and $71.7 \%$, respectively) or with bone metastasis $(85.6 \%, 60.5 \%$, and $44.1 \%$, respectively) [23].

Interobserver agreement in SSTR PET/CT image interpretation was almost perfect when 7 nuclear medicine physicians from 5 different institutions were asked to review SSTR PET/CT scans of 50 NET patients. In particular, reproducibility ranged from substantial to almost perfect for overall scan results and organ/lymph node involvement, and an almost perfect interobserver agreement was also observed for tumor SUVmax assessment (intraclass correlation coefficient 0.99). Liver SUVmax and spleen SUVmean were also highly reproducible (intraclass correlation coefficients of 0.79 and 0.81 , respectively) [26].

Considering the strong link between SSTR expression and receptor-targeted treatment options, SSTR PET/CT strongly influences patients' management. SSTR PET/CT-derived information has been reported to strongly impact the clinical management (from $30 \%$ to $50 \%$ of the cases), by changing either the stage or the clinical strategy $[10,23,27]$.

In a cohort of 90 pathologically confirmed NET cases, DOTANOC PET/CT impacted management in slightly more than half of the patients (50/90 cases, 55\%). Most patients initiated/continued PRRT (27 patients) or SSA (7 patients) treatment after SSTR PET/CT, or were referred to surgery (6 patients). Less common conditions were exclusion from previously planned surgery or PRRT (in SSTR-negative cases), indication to liver transplantation or radiotherapy, and further diagnostic workup [27].

Similar results were portrayed in a much larger study including 1258 PET/CT scans; the treatment plan was changed after 515/1258 (40.9\%) [ $\left.{ }^{68} \mathrm{Ga}\right] \mathrm{Ga}$-DOTA-TATE PET/CT scans because of new, unexpected findings. In most cases, the new treatment comprised initiation of chemotherapy or PRRT (362/515, 70.3\%). In 10.1\% (52/515), PET/CT-derived data were followed by surgery, while in $13.8 \%(71 / 515)$ a new chemotherapy regimen was administered. Less common treatment changes included cessation of previous treatment, exclusion from PRRT, and indication for liver transplant [23].

In an effort to collect stronger clinical evidence, overcoming the limits imposed by the often small numbers of patients included in published cohorts (mostly due to the rarity of the disorder), meta-analytic data were extrapolated. In particular, a recently published umbrella review collected the results of 34 meta-analyses [28], analyzing the diagnostic performance of different radiopharmaceuticals (SSTR PET/CT, [ $\left.{ }^{18} \mathrm{~F}\right] \mathrm{F}-\mathrm{DOPA}$ PET/CT, $\left[{ }^{18}\right.$ F]FFDG PET/CT) in NENs or suspected NETs. The main results derived from metaanalyses of the diagnostic performance of SSTR PET/CT are reported in Table 1 [29-42]. 
Table 1. Diagnostic performance of meta-analysis data on 68Ga-DOTA peptides PET.

\begin{tabular}{|c|c|c|c|c|c|c|c|c|c|}
\hline \multirow[b]{2}{*}{ NENs } & \multirow[b]{2}{*}{ References } & \multirow[b]{2}{*}{ Relevant Study Details } & \multicolumn{3}{|c|}{ Per-Patient } & \multirow{2}{*}{$\begin{array}{c}\text { Per-Lesion } \\
\text { DR or } \\
\text { Sens or Spec (\%) or } \\
\text { ROC-AUC } \\
\end{array}$} & \multirow[b]{2}{*}{ Comments } & \multirow[b]{2}{*}{$\begin{array}{l}\text { Number of } \\
\text { Included } \\
\text { Studies }\end{array}$} & \multirow[b]{2}{*}{$\begin{array}{l}\text { Number of } \\
\text { Included Pts }\end{array}$} \\
\hline & & & $\begin{array}{l}\text { Pooled } \\
\text { Sens\% } \\
(95 \% \text { CI })\end{array}$ & $\begin{array}{l}\text { Pooled } \\
\text { Spec\% } \\
(95 \% \text { CI) }\end{array}$ & $\begin{array}{l}\text { DR (\%) or } \\
\text { ROC-AUC }\end{array}$ & & & & \\
\hline SUSPECTED NET & $\begin{array}{l}\text { Sing } 2018[29] \\
\text { Sing } 2018[29]\end{array}$ & $\begin{array}{c}\text { Initial diagnosis } \\
\text { Staging and restaging }\end{array}$ & $\begin{array}{l}91(85-94) \\
78.3 \text { to } 100\end{array}$ & $\begin{array}{l}94(86-98) \\
83 \text { to } 100\end{array}$ & & & & 22 & na \\
\hline \multirow{7}{*}{$\begin{array}{l}\text { THORACIC } \\
\text { and/or GEP NET }\end{array}$} & Geijer 2013 [31] & All tracers & $93(91-94)$ & $96(95-98)$ & $\begin{array}{l}\text {-AUC } 0.98 \\
(0.95-1.0)\end{array}$ & & & 22 & 2105 \\
\hline & Yang 2014 [32] & $\begin{array}{l}\text { TOC } \\
\text { TATE }\end{array}$ & $\begin{array}{l}93(89-96) \\
96(91-99)\end{array}$ & $\begin{array}{c}85(74-93) \\
100(82-100)\end{array}$ & $\begin{array}{l}\text {-AUC } 0.96 \\
\text { AUC } 0.98\end{array}$ & & & 10 & 416 \\
\hline & Deppen, 2016 [33] & $\begin{array}{l}\text { TATE vs. octrootide and } \\
\text { conventional imaging }\end{array}$ & $\begin{array}{c}90.9 \\
(81.4-96.4)\end{array}$ & $\begin{array}{c}90.6 \\
(77.8-96.1)\end{array}$ & & & TATE superiority & 42 & \\
\hline & Piccardo 2021 [35] & $\begin{array}{c}\text { Intestinal NET } \\
\text { (head to head, all tracers vs. } \\
{\left[{ }^{18} \mathrm{~F}\right] \mathrm{F}-\mathrm{DOPA} \text { ) }}\end{array}$ & 88 & na & & Sens 82 & $\begin{array}{c}{\left[{ }^{18} \text { F]F-DOPA superiority only }\right.} \\
\text { per lesion }(95 \%) \text { but not per } \\
\text { patient }(83 \%)\end{array}$ & 6 & 112 \\
\hline & Jiang 2019 [36] & $\begin{array}{l}\text { Pulmonary carcinoids (all } \\
\text { tracers vs. }\left[{ }^{18} \mathrm{~F}\right] \mathrm{FDG} \text { ) }\end{array}$ & $90(82.0-95.0)$ & & & & $\begin{array}{l}\text { Higher SSTR uptake in typical } \\
\text { carcinoids than atypical ones; } \\
\text { FDG overall sens } 71 \\
(66.0-76.0)\end{array}$ & 14 & 352 \\
\hline & & All grades, all tracers & $92(0.89-0.95)$ & $91(0.83-0.95)$ & $\begin{array}{l}\text { AUC } 0.96 \\
(0.94-0.98)\end{array}$ & $\begin{array}{l}\text { Sens } 95(0.86-0.98) ; \\
\text { spec93 }(0.83-0.97) ; \\
\text { AUC } 0.98(0.96-0.99)\end{array}$ & & 30 & 3401 \\
\hline & & $\begin{array}{c}\text { G1 } \\
\text { G2 } \\
\text { G3 } \\
\text { TOC } \\
\text { TATE } \\
\text { NOC } \\
\end{array}$ & $\begin{array}{l}92 \\
90 \\
58 \\
95 \\
92 \\
87 \\
\end{array}$ & $\begin{array}{l}91 \\
88 \\
90 \\
\end{array}$ & & & & & \\
\hline \multirow[b]{2}{*}{ CUP-NET } & Ma $2021[38]$ & All tracers & 82 & 55 & AUC 69; DR 61; & & \multirow[b]{2}{*}{$\begin{array}{l}\text { Most frequent sites of CUP: } \\
\text { bowel and pancreas. }\end{array}$} & 10 & 484 \\
\hline & De Dosso 2019 [39] & All tracers & & & DR 56 (48-63) & & & 12 & 383 \\
\hline \multirow[b]{2}{*}{ PGL } & Kan 2018 [40] & $\begin{array}{l}\text { All tracers vS. FDG } \\
\text { without germline } \\
\text { mutations; } \\
\text { with germline mutations }\end{array}$ & $\begin{array}{c}95(0.92-0.97) \\
97\end{array}$ & $\begin{array}{c}87(0.63-0.96) \\
79\end{array}$ & $\begin{array}{l}\text { AUC } 0.78 \\
(0.74-0.81)\end{array}$ & & $\begin{array}{l}\text { FDG: sens } 85 \text { and spec } 55 \text {; } \\
\text { AUC } 0.88(0.85-0.91)\end{array}$ & 17 & 629 \\
\hline & Han 2019 [41] & $\begin{array}{l}\text { All tracers vs. DOPA, FDG, } \\
\text { MIBG }\end{array}$ & & & DR 93 (91-95) & & $\begin{array}{c}\text { DR }\left[{ }^{18} \text { F]FDOPA PET } 80\right. \\
\text { (69-88), }\left[^{18} \text { F]FDGPET } 74\right. \\
\text { (46-91), and [123/131 I]MIBG } \\
\text { scan } 38 \text { (20-59). SSTR DR } \\
\text { superiority, particularly head } \\
\text { and neck PGL. }\end{array}$ & 9 & 215 \\
\hline rMTC & Treglia 2017 [42] & All tracers & & & & DR 63.5 (49-77) & $\begin{array}{l}\text { SSTR PET DR } 83 \% \text { if calcitonin } \\
>500 \mathrm{ng} / \mathrm{L} ;{ }^{18}{ }^{8} \mathrm{~F} \text { FDOPA is } \\
\text { recommended in this setting }\end{array}$ & 9 & \\
\hline
\end{tabular}

Table legend: NEN: neuroendocrine neoplasia; NET: neuroendocrine tumor; GEP: gastroenteropancreatic; CUP: cancer of unknown primary site; PGL: paraganglioma; rMTC: recurren medullary thyroid cancer; CI: confidence interval; DR: detection rate; sens: sensitivity; spec: specificity; SSTR: somatostatin receptor; ROC: receiver operating characteristics; AUC: area under the curve; na = not available. 
Overall, SSTR PET/CT (using either NOC, TOC, or TATE) is the standard and preferred imaging modality to functionally study well-differentiated NETs, showing high per-patient pooled sensitivity and specificity respectively (both $>90 \%$ for lung and GEP NETs). SSTR $\mathrm{PET} / \mathrm{CT}$ is also valuable for the detection of head and neck paraganglioma, while it shows a lower detection rate for abdominal forms. Lower accuracy is generally expected for MTC and CUP 1.

Meta-analysis data also confirm that a change in management occurs in more than onethird of the cases. In particular a systematic review and meta-analysis evaluated the clinical impact of SSTR PET/CT, analyzing a total of 1561 NET patients in 14 studies. Overall, a change in management occurred in 44\% (range, 16-71\%) of patients. Furthermore 7 of 14 studies differentiated between inter- and intramodality changes, with most changes being intermodality (77\% vs. $23 \%)$ [10].

\subsection{Quantification}

Quantification of radiopharmaceuticals' uptake is recommended in PET/CT reports, and may provide an indirect measure of cells' differentiation. In fact, SSTR PET/CT sensitivity varies between tumor types on the basis of SSTR density; high uptake has been largely demonstrated in most low-grade, highly differentiated NETs (i.e., GEP, lung NETs, sympathoadrenal system tumors, meningioma), usually expressing high SSTR density.

In 2010, Campana et al. reported that $\left[{ }^{68} \mathrm{Ga}\right] \mathrm{Ga}$-DOTA-NOC PET/CT SUVmax was correlated with the clinical and pathological features of NETs, and might therefore be used for prognostication (in fact, lesions with higher SUVmax and, therefore, higher SSTR expression, have a lower grade and a better prognosis). In line with these data, similar results were observed in pancreatic G1 and G2 NETs; significant differences in progressionfree survival (PFS) were observed in relation to Ki-67 (median, 45 months for Ki- $67 \leq 5 \%$ and 20 months for Ki-67>5\%; $p=0.005$ ), SUVmax (<37.8 vs. >38.0: 16.0 vs. 27.0 months; $p=0.002$ ), and type of therapy (medical vs. peptide receptor radionuclide therapy: $16.0 \mathrm{vs}$. 26.0 months; $p=0.014$ ) [43].

Interestingly, in 10 patients with metastatic neuroendocrine tumors who underwent a 45-minute dynamic acquisition followed by three whole-body PET/CT examinations at 1,2 , and $3 \mathrm{~h}$ after injection with both $\left[{ }^{68} \mathrm{Ga}\right] \mathrm{Ga}$-DOTA-TOC and $\left[{ }^{68} \mathrm{Ga}\right] \mathrm{Ga}-D O T A-T A T E$, SUV did not correlate linearly with $\mathrm{Ki}-67$, and achieved saturation for a Ki of greater than $0.2 \mathrm{~mL} / \mathrm{cm}^{3} / \mathrm{min}$, corresponding to an SUV of more than 25 . Thus, SUV may not reflect the SSTR density accurately at its higher values. Therefore, in patients with elevated SSTR expression and a large tumor burden, a limiting step for tracer uptake might be due to plasma peptide availability and receptor saturation [44].

In fact, from a merely prognostic point of view, the radiopharmaceutical that is most certainly able to provide more clinically relevant prognostic data is $\left[{ }^{18} \mathrm{~F}\right] \mathrm{FDG}$, since it can demonstrate the presence of more aggressive clones that will ultimately drive the patient's prognosis.

SUVmax thresholds were also proposed to select patients eligible for PRRT. In a study including 40 patients with advanced-stage NETs treated with a fixed dose of [ $\left.{ }^{90} \mathrm{Y}\right] \mathrm{Y}$-DOTATOC (5550 or $3700 \mathrm{MBq})$, using a [ $\left.{ }^{68} \mathrm{Ga}\right] \mathrm{Ga}$-DOTA-TOC SUVmax $>17.9$ as the cutoff for favorable outcomes, PET was able to predict the treatment response of all responders and of 15/16 non-responders. All four patients with equivocal findings showed an SUV $\leq 17.9$, and soon experienced tumor progression [45].

A comparable threshold was found by a group from Heidelberg, assessing 60 liver metastases in 30 NET patients at baseline and after PRRT. Using a threshold value of $>16.4$ for SUVmax, the sensitivity and specificity in predicting responding lesions were 95 and $60 \%$, respectively [46]. 
However, it is well known that absolute SUV values are affected by several biases, especially due to the difficulty of standardization between different scanners and technologies. The tumor-to-liver ratio (TLR, calculated as lesion SUVmax divided by SUVmean of the liver) and tumor-to-spleen ratio (TSR) are scanner-independent criteria that enable the translation of results to other institutions. In the same German study, [ $\left.{ }^{68} \mathrm{Ga}\right] \mathrm{Ga}-\mathrm{DOTA}-\mathrm{TOC}$ TLR of 2.2 was predictive of a good response [46].

In a recent meta-analysis, a high interobserver agreement on the overall scan interpretation as well as in the assessment of SUVmax values (of the primary tumor as well as in the liver background) was reported [26].

Volumetric functional features have been also explored; for example, SSTR-expressing tumor volume (SRETV) (e.g., segmented at 50\% of the SUVmax) and total lesion SSTR (TLSRE $=$ SSTR-expressing tumor volume $\times$ tumor SUVmean). In particular, WHO tumor grade and the sum of all SRETVs have been reported to be independent predictors of PFS [47].

Certainly, SUVmax values should always be interpreted critically, taking into account the many factors that can affect its measure; however, it is important to underline that SUVmax can provide valuable data, especially regarding whole tumor volume, cells' differentiation, and the potential heterogeneity of SSTR expression, all of which will ultimately have an impact on management. Therefore, it is clinically relevant to indicate the SUVmax value of the most relevant lesions (e.g., the ones with the highest uptake, or lesions presenting a low SUVmax that may require further investigation).

From a clinical point of view, all lesions presenting an uptake higher than that of the liver are considered as presenting pathological SSTR expression. This criterion may, however, not be applicable to very small lesions (affected by partial volume effect, e.g., millimetric ileum NET) or in cases with extensive metastatic liver involvement (in which the assessment of SUVmax of the liver background is practically impossible).

The visual assessment of uptake intensity by comparing tumor uptake with the liver background was first proposed by means of the Krenning score-a visual five-point scale first developed for Octreoscan ${ }^{\mathrm{TM}}$ in 1993 [48]. More recently, the scale was adapted to fit SSTR PET/CT as the modified Krenning score [49], and is currently applied in clinical practice to guide PRRT eligibility (0: no uptake, <blood pool; 1: very low, <liver; 2: = liver; 3: >liver but <spleen; 4: = or >spleen). Head-to-head analysis demonstrates higher Krenning scores for [ ${ }^{68} \mathrm{Ga}$ ]Ga-DOTA-TATE PET/CT compared to ${ }^{111} \mathrm{In}$-pentetreotide, particularly when lesions measure $2 \mathrm{~cm}$ or less. In fact, small lesion size resulted in low Krenning scores using ${ }^{111}$ In-pentetreotide, but lesion size did not affect SSTR PET-based Krenning scores [49]. The use of a visual criterion of uptake (uptake equal or higher than the liver) is also recommended by the American College of Radiology (ACR), for [ $\left.{ }^{68} \mathrm{Ga}\right] \mathrm{Ga}-\mathrm{DOTA}-$ TATE [50] to identify patients likely to respond SSTR targeted treatments.

\subsection{Standardized Reporting}

A structured reporting system, entitled SSTR-RADS version 1.0, was proposed in the effort to standardize assessment for both diagnosis and treatment planning in neuroendocrine tumors. This system consists of a five-point scale assessing the likelihood of malignancy (from grade 1-negligible, benign—to grade 5: high probability of NET), a three-point score of the uptake intensity of the largest and most avid lesion, and a summed RAD score considering the scores of five target lesions [51-53].

In line with the concept of medical practice harmonization, a novel ENETS standardized (synoptic) reporting system was proposed [54]; a multidisciplinary panel performed a wide discussion and literature review in order to develop a synoptic template for SSTR PET/CT reporting. Nuclear medicine readers are encouraged to implement the following elements in their current reporting practice: 
- Clinical details (e.g., indication, primary location, pathology, inherited/ clinical syndrome);

- Procedure (e.g., radiopharmaceutical, administered activity, uptake time, scan type, field of view, interventions);

- $\quad$ Comparative imaging (e.g., modality, radiopharmaceutical);

- $\quad$ Findings (e.g., primary location: size and avidity using Krenning score; nodes: locoregional vs. distant; metastases: locations and characteristics, e.g., number, size, heterogeneity, necrosis, Krenning score);

- $\quad$ For reference lesions, location, visual avidity (e.g., Krenning score), semi-quantitative avidity (e.g., SUVmax, TSR, SSTR-FDG relationship), and size (uni- or bidimensional) should be included [54].

\subsection{SSTR for Response Assessment}

The role of SSTR PET/CT is still unclear for the response assessment scenario; EANM 2017 guidelines recommend the use of RECIST for response assessment [14]. ENETS 2017 guidelines also recommend the use of the RECIST criteria in PanNETs [6].

Although the RECIST criteria represent the gold standard to assess response in oncology, they are not ideal in the NEN setting, since these are typically slow-growing tumors that may present cystic components. The integration of morphological features with density data (CHOI criteria, originally applied to gastrointestinal stromal tumors) was proposed but not validated [55].

To date, no definite response criteria have been validated for PET/CT. Moreover, $\mathrm{PET} / \mathrm{CT}$ is not routinely performed at interim, nor at the end of treatment. It is well known that variations in the lesions' SUVmax values are not always an indicator of response (e.g., reduced uptake after therapy might reflect a good response but also a loss of SSTR expression due to tumor dedifferentiation [17]. SUVmax alone does not account for intralesional variation of SSTR expression, and further prospective studies are warranted to validate the other quantitative parameters already reported in the previous paragraph (see Section 2.5). In clinical practice, it is crucial to identify the disappearance of previous lesions or the appearance of new lesions rather than to measure SUV changes.

Even at the recent EANM FOCUS3 consensus, there was no agreement on the best imaging modality for PRRT treatment monitoring. However, it is interesting to note that the majority of panelists (approximately 58\%) voted for a combination of SSTR PET/CT and triple-phase contrast-enhanced dCT and/or MRI as their preferred imaging modality $[18,19]$.

\subsection{PET/CT for Prognostication}

In view of the close relationship between SSTR expression and treatment options (with non-radioactive and radioactive SSTR analogues), lesions presenting high uptake of $\left[{ }^{68} \mathrm{Ga}\right] \mathrm{Ga}-\mathrm{DOTA}$ peptides are associated with better outcomes $[43,46,56]$.

On the other hand, low SUVmax values are associated with shorter PFS and OS (overall survival) in patients NETs [57]. Moreover, high overall tumor burden (classified as limited: <five lesions at one site; moderate: > five lesions at two sites; or extensive: >two sites) and tumor heterogeneity are associated with worse prognosis [58].

Pancreatic NENs also show differences in prognosis depending on disease distribution, with worse prognosis if $>25 \%$ of the liver and bone metastases are present. In particular, liver metastases at diagnosis significantly decrease survival in most GEP NETs [59].

Visual assessment of SSTR heterogeneity was demonstrated to be both predictive and prognostic in G1 or G2 NET patients $(n=65)$ undergoing PRRT ( $2-5$ cycles). Patients with heterogeneous SSTR expression on target lesions $(n=28 / 65 ; 44.4 \%)$ had a significantly lower OS ( $p=0.01)$ and time to progression (TTP; 26 months vs. 54 months, log-rank $p=0.013)$. Moreover, the quality of SSTRs was found to be the only independent prognostic factor for $\mathrm{OS}(p=0.04 ; \mathrm{HR}=3.68)$ and TTP $(p=0.03 ; \mathrm{HR}=3.09)$ at multivariate analyses [60]. 
Currently, heterogeneity in SSTR distribution at the lesional level is followed by $\left[{ }^{18} \mathrm{~F}\right] \mathrm{FDG}$ PET/CT imaging. $\left[{ }^{18} \mathrm{~F}\right] \mathrm{FDG}$ is a marker of the glycolytic metabolism, and is highly taken up by high-grade, poorly differentiated tumors, such as high-grade G2 (Ki$67>10 \%)$, NET G3, or NEC. Therefore, $\left[{ }^{18} \mathrm{~F}\right] \mathrm{FDG}$-positivity is correlated with the worst prognosis [61-65].

Current EANM/ENETS guidelines $[6,8,14]$ recommend $\left[{ }^{18} \mathrm{~F}\right] \mathrm{FDG}$ PET/CT in NETs for staging G3 and for higher grade G2 (Ki-67 > 10\%). Moreover, $\left[{ }^{18} \mathrm{~F}\right] \mathrm{FDG}$ PET/CT is recommended in the event of mismatched lesions (dCT-positive/SSTR PET-negative) or rapid progression $[18,19]$.

$\left[{ }^{18} \mathrm{~F}\right]$ FDG uptake was reported in around $40 \%$ of G1 NETs and nearly all G3 NETs. In thoracic/GEP NETs, the per-patient pooled sensitivity, derived in a recent meta-analysis by Liu et al., was 70\% (by grade: 38\% G1; 55\% G2; 71\% G3) [37]. It is interesting to note that most papers investigating the role of $\left[{ }^{18} \mathrm{~F}\right] \mathrm{FDG}$ PET/CT in NENs often fail to report the timeframe between the first pathological grade assessment and [ $\left.{ }^{18} \mathrm{~F}\right] \mathrm{FDG}$-positivity; therefore, it is difficult to determine whether the $\left[{ }^{18} \mathrm{~F}\right] \mathrm{FDG}$ uptake was assessed in a true G1 lesion or in an initial dedifferentiation of a previously reported G1 lesion [37].

Optimal diagnostic performances were demonstrated in small-cell lung cancer (SCLC) and Merkel-cell carcinoma (MCC). In particular, in SCLC, a pooled sensitivity and specificity of 97.5 and $98 \%$ were reported, respectively, for the assessment of extensive disease pre-therapy [66], whereas in MCC a pooled sensitivity and specificity of 90 and 98\%, respectively, were documented [67].

$\left[{ }^{18} \mathrm{~F}\right]$ FDG-negativity pre-PRRT in thoracic/GEP NETs was associated with prolonged PFS and OS [68]. On the other hand, higher $\left[{ }^{18}\right.$ F]FDG uptake was associated with worse EFS and OS [69]. Furthermore, the association between higher values of $\left[{ }^{18} \mathrm{~F}\right] \mathrm{FDG}$ quantitative parameters (such as $\left.{ }^{18} \mathrm{~F}\right]$ FDG SUVmax of the primary lesion, metabolic tumor volume, total lesion glycolysis) and inferior EFS, PFS, and OS was demonstrated [70].

In recent years, Chan et al. proposed a grading system where the findings from the combined reading of SSTR-PET/CT and [ ${ }^{18}$ F]FDG PET/CT are integrated into a single parameter-the "NETPET" score [71]. Despite needing validation in larger prospective studies, this represents a promising biomarker for a wide range of NENs, already showing successful results in bronchial NENs as well as GEP NENs [72].

It is likely that the optimal biological characterization would be achieved with a combined use of SSTR and $\left[{ }^{18}\right.$ F]FDG PET/CT to non-invasively assess disease heterogeneity and predict PRRT response [71,73]. In line with this approach, the ESMO 2020 guidelines [74] also envision the use of double-tracer ([ ${ }^{18}$ F]FDG +SSTR) PET/CT for all G2-G3 NETs in order to achieve the optimal disease characterization (Figure 1).

In fact, this diagnostic synergy is expected to enable the better selection of the most appropriate treatment option (i.e., PRRT alone vs. PRRT combined with targeted external radiotherapy/chemotherapy/alternative treatments), while also identifying the ratio of differentiated to de-differentiated disease burden at which PRRT fails to be beneficial. 


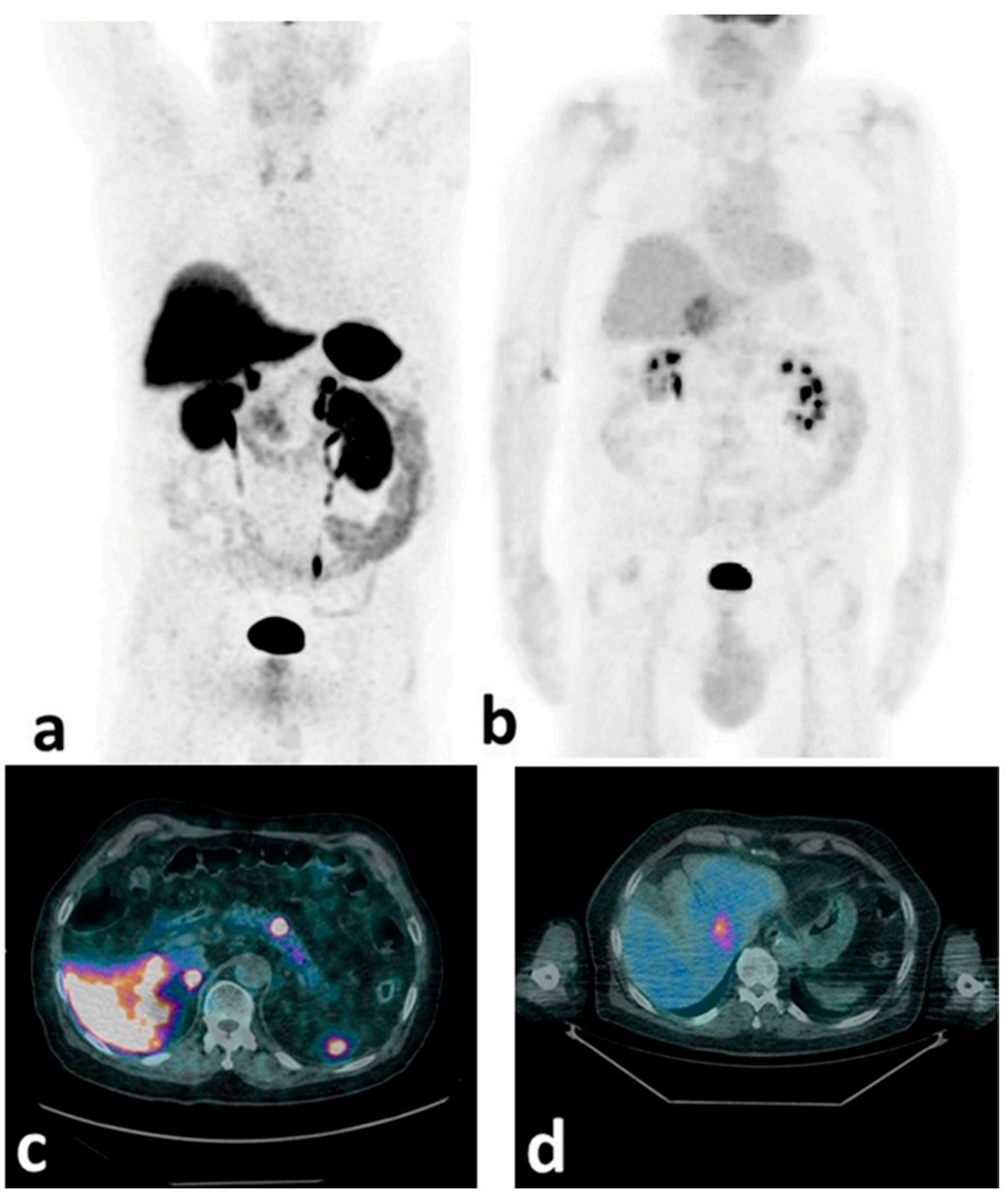

Figure 1. $\left[{ }^{68} \mathrm{Ga}\right] \mathrm{Ga}-\mathrm{DOTA}-\mathrm{NOC}$ and $\left[{ }^{18} \mathrm{~F}\right] \mathrm{FDG}$ mip $(\mathbf{a}, \mathbf{b})$ and transaxially fused (c,d) PET/CT images of a patient with a pancreatic G2 NET (Ki-67 = 12\%). High SSTR expression is observed in the primary pancreatic body lesion $(\mathbf{a}, \mathbf{c})$, while significant $\left[{ }^{18} \mathrm{~F}\right] \mathrm{FDG}$ uptake $(\mathbf{b}, \mathbf{d})$ is detected at the liver metastatic level (SSTR-negative). This case shows the potential of the double-tracer PET/CT approach in demonstrating NET de-differentiation.

\subsection{Agonists Labelled with Fluorine}

${ }^{18}$ F-labelled SSTR agonists may overcome the practical, regulatory, and economic barriers related to ${ }^{68} \mathrm{Ge} /{ }^{68} \mathrm{Ga}$ generators (e.g., limited availability of FDA- and European Medical Agency (EMA)-approved generators, relatively short ${ }^{68} \mathrm{Ga}$ half-life, low activity amounts after single elution that hamper the clinical availability of ${ }^{68} \mathrm{Ga}$-labeled PET tracers). Moreover, fluorinated radiopharmaceuticals could be produced centrally and peripherally distributed; ${ }^{18} \mathrm{~F}$ has a longer half-life (110 min vs. $68 \mathrm{~min}$ of $\left.{ }^{68} \mathrm{Ga}\right)$ and shorter positron range $\left(0.6 \mathrm{~mm}\right.$ vs. $3.5 \mathrm{~mm}$ of $\left.{ }^{68} \mathrm{Ga}\right)$ suitable for high-resolution imaging [75].

Recently, two radiopharmaceuticals were studied: $\left[{ }^{18} \mathrm{~F}\right]-\mathrm{AlF}-\mathrm{NOTA}$-octreotide and $\left[{ }^{18} \mathrm{~F}\right]-S i F A l i n-T A T E$, both presenting biodistribution similar to that of $\left[{ }^{68} \mathrm{Ga}\right]-S S T R$ and preferential uptake in well-differentiated NETs $[76,77]$. Interestingly, the preferential $\left[{ }^{18} \mathrm{~F}\right]$ AlF-NOTA-octreotide uptake time was 120 min post-injection (p.i.) [76], although it was also acquired at $60 \mathrm{~min}$ [78].

A first-in-human study evaluated $\left[{ }^{64} \mathrm{Cu}\right] \mathrm{Cu}$-SARTATE (MeCOSar-Tyr3-octreotate) for imaging 10 NET patients; optimal images were acquired at $4 \mathrm{~h}$ p.i., although in $9 / 10$ patients if acquired at $1 \mathrm{~h}$ p.i. it was comparable with $\left[{ }^{68} \mathrm{Ga}\right] \mathrm{Ga}$-DOTA-TATE PET/CT [79]. 


\subsection{Future Imaging Prospects}

\subsubsection{Artificial Intelligence}

Artificial intelligence could be used to extract image features from medical images in order to build diagnostic, predictive, and prognostic models. In particular, it could be employed to provide a signature (that is, a combination of features) that is not necessarily visible to the naked eye-even an expertly trained one. Although radiomics has shown promising preliminary results in identifying tumor subtypes and aggressiveness, as well as in predicting responses to therapy and the outcomes for patients with various cancers, most of these results have been obtained in small, retrospective, monocentric cohorts, often employing different methods for lesion segmentation and feature extraction [80]. It is currently difficult to generalize the results obtained in published papers due to excessive data heterogeneity; indeed, the application of AI in clinical practice requires absolute methodological harmonization [81]. Thus far, few papers have addressed the use of PET/CT-derived features for the assessment of NENs (Table 2) [82-88].

Table 2. PET/CT-derived radiomic features for the assessment of NENs.

\begin{tabular}{|c|c|c|c|c|c|c|c|c|}
\hline Author & $\begin{array}{c}\text { Journal, } \\
\text { Publication Date }\end{array}$ & Ref & Clinical Setting & $\underset{\text { Site }}{\text { Primary }}$ & Modality & Tracer & $\begin{array}{c}\text { Number of } \\
\text { Patients }\end{array}$ & Methods \\
\hline Atkinson C & $\begin{array}{l}\text { Frontiers in } \\
\text { Oncology, } 2021\end{array}$ & [82] & $\begin{array}{l}\text { Prognosis / } \\
\text { PRRT }\end{array}$ & Multiple* & $\mathrm{PET} / \mathrm{CT}$ & $\begin{array}{c}{\left[{ }^{68} \mathrm{Ga}\right] \mathrm{Ga}-} \\
\text { DOTA-TATE }\end{array}$ & 44 & $\begin{array}{l}\text { TexRAD research software, } \\
\text { Cambridge, UK }\end{array}$ \\
\hline Bevilacqua A & $\begin{array}{l}\text { Diagnostics } \\
\text { (Basel), } 2021\end{array}$ & [87] & $\begin{array}{l}\text { Tumor grade } \\
\text { prediction }\end{array}$ & pNET & $\mathrm{PET} / \mathrm{CT}$ & $\begin{array}{c}\left.{ }^{68} \mathrm{Ga}\right] \mathrm{Ga}- \\
\text { DOTA-NOC }\end{array}$ & 58 & $\begin{array}{l}\text { ImageJ + in-house- } \\
\text { generated model }\end{array}$ \\
\hline Thuillier P & Biomedicines, 2021 & [83] & $\begin{array}{l}\text { Pathological } \\
\text { classification }\end{array}$ & Lung NEN & $\mathrm{PET} / \mathrm{CT}$ & {$\left[{ }^{18} \mathrm{~F}\right] \mathrm{FDG}$} & 44 & $\begin{array}{c}\text { LIFEx v.6.0 (IMIV / CEA, } \\
\text { Orsay, France }\end{array}$ \\
\hline Liberini V & $\begin{array}{c}\text { EJNMMI } \\
\text { Physics, } 2021\end{array}$ & [84] & Segmentation & Multiple \$ & $\mathrm{PET} / \mathrm{CT}$ & $\begin{array}{l}{\left[{ }^{68} \mathrm{Ga}\right] \mathrm{Ga}-} \\
\text { DOTATOC }\end{array}$ & 49 & $\begin{array}{c}\text { LifeX v.4.81 (IMIV/CEA, } \\
\text { Orsay, France }\end{array}$ \\
\hline Liberini V & $\begin{array}{l}\text { Frontiers in Medicine } \\
\text { (Lausanne), } 2021\end{array}$ & [85] & PRRT outcome & $\begin{array}{l}\text { G3 NET } \\
\text { (pancreas, } \\
\text { rectum) }\end{array}$ & $\mathrm{PET} / \mathrm{CT}$ & $\begin{array}{c}{\left[{ }^{68} \mathrm{Ga}\right] \mathrm{Ga}-} \\
\text { DOTATOC } / \\
{\left[{ }^{18} \mathrm{~F}\right] \mathrm{FDG}}\end{array}$ & 2 & $\begin{array}{l}\text { LIFEx v.5.10 (IMIV /CEA, } \\
\text { Orsay, France) }\end{array}$ \\
\hline Mapelli P & $\begin{array}{l}\text { Nuclear Medicine } \\
\text { Communications, } \\
2020\end{array}$ & [88] & $\begin{array}{l}\text { Pre-operative } \\
\text { risk assessment }\end{array}$ & $\mathrm{pNEN}$ & $\mathrm{PET} / \mathrm{CT}$ & $\begin{array}{c}{\left[{ }^{68} \mathrm{Ga}\right] \mathrm{Ga}-} \\
\text { DOTATOC/ } \\
{\left[{ }^{18} \mathrm{~F}\right] \mathrm{FDG}}\end{array}$ & 61 & $\begin{array}{c}\text { Chang-Gung Image } \\
\text { Texture Analysis } \\
\text { software package }\end{array}$ \\
\hline Weber M & BMC Cancer, 2020 & [86] & $\begin{array}{l}\text { Treatment- } \\
\text { related } \\
\text { changes }\end{array}$ & & PET/MRI & $\begin{array}{l}\left.{ }^{68} \mathrm{Ga}\right] \mathrm{Ga}- \\
\text { DOTATOC }\end{array}$ & 18 & $\begin{array}{l}\text { LIFEx v.6.0 (IMIV /CEA, } \\
\text { Orsay, France }\end{array}$ \\
\hline
\end{tabular}

Legend: ${ }^{*}=$ carcinoid, pancreatic, thyroid, head and neck, catecholamine-secreting, and unknown primary NET; $\$=\mathrm{GEP}+$ lung + other; Ref = reference.

\subsubsection{SSTR Antagonists}

Promising preclinical data support the development of new radiopharmaceuticals that act as antagonists of the SSTR. In vitro studies have demonstrated that antagonists recognize a larger number of binding sites and lack internalization after binding [89]. In humans, antagonists show remarkably low background (especially in SSTR-2-positive organs), resulting in easier lesion detection-especially at the liver level [90-92]

Thus far, two theranostic pairs of JR11 have been studied- $\left[{ }^{68} \mathrm{Ga}\right] \mathrm{Ga}-\mathrm{DOTA}-J \mathrm{R} 11 /\left[{ }^{177} \mathrm{Lu}\right]$ Lu-DOTA-JR11 and [ $\left.{ }^{68} \mathrm{Ga}\right]$ Ga-NODAGA-JR11/[ $\left.{ }^{177} \mathrm{Lu}\right] \mathrm{Lu}-\mathrm{DOTA}-J R 11$ - in limited patient cohorts $[93,94]$.

The most promising radiopharmaceutical seems to be $\left[{ }^{68} \mathrm{Ga}\right] \mathrm{Ga}-N O D A G A-J R 11$ (as compared to [ ${ }^{68} \mathrm{Ga}$ ]Ga-DOTA-JR11), showing an SSTR-2 affinity $\left(\mathrm{IC}_{50}=1.2 \mathrm{nmol} / \mathrm{L}\right)$ similar to that of $\left[{ }^{177} \mathrm{Lu}\right] \mathrm{Lu}-\mathrm{DOTA}-J R 11$ (IC50 = $\left.0.73 \mathrm{nmol} / \mathrm{L}\right)$ [92].

Another promising theranostic pair is [ $\left.{ }^{68} \mathrm{Ga}\right] \mathrm{Ga}-\mathrm{DOTA} / \mathrm{NODAGA}-\mathrm{LM} 3$ and $\left[{ }^{177} \mathrm{Lu}\right] \mathrm{Lu}-$ DOTA-LM3, showing high tumor retention and favorable dosimetry $[95,96]$.

\section{Somatostatin Analogues for Targeted Therapy}

\subsection{PRRT: From Early Studies to Approval}

Radiolabeled somatostatin analogues were first employed to diagnose NEN, but they can also be used for treatment when labelled with isotopes emitting cytotoxic radiation. In particular, while $\left[{ }^{68} \mathrm{Ga}\right] \mathrm{Ga}-D O T A-T O C$ and $\left[{ }^{68} \mathrm{Ga}\right.$ ]Ga-DOTA-TATE can be used to image SSTR-expressing NENs, [ $\left.{ }^{90} \mathrm{Y}\right] \mathrm{Y}-\mathrm{DOTA}-\mathrm{TOC}$ and $\left[{ }^{177} \mathrm{Lu}\right] \mathrm{Lu}-\mathrm{DOTA}-\mathrm{TATE}$ have also been employed for PRRT. Theranostics is an emerging field of nuclear medicine that combines 
diagnostics with targeted radionuclide therapy, and can be considered to be the epitome of personalized medicine [97]. In fact, the use of PRRT in NEN patients is not new, since it has been used for the treatment of metastatic and inoperable NETs for $~ 30$ years in the setting of clinical trials. This consists of the systemic administration of a stable somatostatin analogue labeled with a $\beta$-minus ( $\beta$-)-emitting radioisotope (e.g., $\left[{ }^{90} \mathrm{Y}\right]$ or $\left[{ }^{177} \mathrm{Lu}\right]$ ) that binds to SSTRs overexpressed in target tumor cells [98]. The receptor-peptide complex is internalized by endocytosis, enabling the delivery of cytotoxic radiation directly to the target cells $[99,100]$. The radiopeptide is retained in the receptor-expressing tumor cells and, due to its relatively low molecular weight, it is rapidly cleared from the blood [101].

The interest in PRRT has steadily increased over the years. An analysis of the literature published from 2000 to 2019 reported that the number of papers on PRRT was more than 20 in 2010, was more than 60 in 2015, and was even higher (111) in 2019 [102].

Early therapeutic studies used [ $\left.{ }^{111} \mathrm{In}\right] \mathrm{In}-\mathrm{DTPA}$-octreotide in the mid-to-late 1990s [103-105]. The idea of Krenning et al. was to use the specific physical characteristics of the Auger emission and conversion electrons of [ $\left.{ }^{111} \mathrm{In}\right]$ for therapy; the first patient, with an inoperable, metastasized NET (glucagonoma), was successfully treated with high doses of [ ${ }^{111}$ In]In-pentetreotide [106]. Although there was evidence of some efficacy and minimal toxicity, this treatment presented several disadvantages-it was expensive, it was difficult to deliver a sufficient radioactive dose to the tumor and, due to the ${ }^{111}$ In emission's short tissue range, it resulted in modest tumor shrinkage. For the abovementioned reasons, ${ }^{111} \mathrm{In}$ was soon replaced by novel, more promising alternatives, such as the beta minus emitters yttrium-90 $\left({ }^{90} \mathrm{Y}\right)$ and lutetium-177 $\left({ }^{177} \mathrm{Lu}\right)$ — the currently most widely used isotopes combined with DOTA-TOC or DOTA-TATE, respectively.

${ }^{90} \mathrm{Y}$ has a half-life of 2.7 days, an average $\beta$-energy of $935 \mathrm{keV}$, and a mean particle penetration range of $3.9 \mathrm{~mm}$. This radionuclide is a long-range pure particle emitter, and may be advantageous in comparison to ${ }^{177} \mathrm{Lu}$ when dealing with larger tumors.

${ }^{177} \mathrm{Lu}$ is a medium-energy $\beta$-emitter with a maximum energy of $0.5 \mathrm{MeV}$ and a maximal tissue penetration of $2 \mathrm{~mm}$; ${ }^{177} \mathrm{Lu}$ also emits low-energy $\gamma$-rays at 208 and $113 \mathrm{keV}$, with 10 and $6 \%$ abundance, respectively. Early-phase PRRT trials employed either $\left[{ }^{90} \mathrm{Y}\right] \mathrm{Y}$-DOTATOC or $\left[{ }^{177} \mathrm{Lu}\right] \mathrm{Lu}$-DOTA-TATE, obtaining good response rates - especially in patients with GEP NETs (disease control rates ranging from $66 \%$ to $92 \%$ ) [107-117].

To improve PRRT efficacy, the combination of ${ }^{90} \mathrm{Y}$ and ${ }^{177} \mathrm{Lu}$ treatment regimens has been proposed, in order to exploit the different soft tissue penetration range of the $\beta$-emitted radiation [118].

In addition to efficacy studies, many early papers investigated the toxicity profile of PRRT, especially focused on the effects on the kidneys and bone marrow. Many papers reported the long-term incidence of bone marrow toxicity following $\left[{ }^{177} \mathrm{Lu}\right] \mathrm{Lu}$-DOTA-TATE and [ $\left.{ }^{90} \mathrm{Y}\right] \mathrm{Y}$-DOTA-TOC PRRT; however, hematological toxicity-such as acute leukemia or myelodysplastic syndrome (AL or MDS) — was reported in a minority of patients. In a study including 1109 patients, severe toxicity was observed in $12.8 \%$ of patients (3-4 hematological toxicity: $0.1 \%$ of AL and $0.1 \%$ of MDS) [119]. Overall, the risk of the development of myeloproliferative disorders was reported to be $2 \%$ [119-122].

Due to the mainly renal excretion of these tracers, renal toxicity was also reported, even when a kidney protection protocol (consisting of the infusion of positively charged aminoacidic infusion) was implemented. This latter strategy, however, reducing the radiopharmaceutical's renal uptake, was reported to reduce the frequency of severe renal toxicity (grade 3/4) to less than 3\% of cases [123-125].

Unfortunately, early studies were mainly retrospective phase I-II trials, and were difficult to compare due to their heterogeneous patients cohorts and treatment schemes (in terms of total injected activity, activity per cycle, time intervals between cycles, and number of cycles) $[109,110,112,126-129]$. In 2017, the publication of the NETTER-1 trial results significantly changed the clinical employment of PRRT, and paved the way for the approval of [ $\left.{ }^{177} \mathrm{Lu}\right] \mathrm{Lu}$-DOTA-TATE PRRT in the United States and Europe [130]. The NETTER-1 study was a multinational, open-label, phase III randomized clinical trial that 
evaluated PRRT safety and efficacy in patients with advanced, progressive, SSTR-positive, well-differentiated midgut NETs. A total of 229 patients were randomized a the PRRT arm (treated with four infusions of $7.4 \mathrm{GBq}\left[{ }^{177} \mathrm{Lu}\right] \mathrm{Lu}$-DOTA-TATE every 8 weeks plus $30 \mathrm{mg}$ of octreotide every 4 weeks for symptom control) and a control arm (treated with off-label FDA-approved high-dose $(60 \mathrm{mg})$ octreotide every 4 weeks). Treatment with $\left[{ }^{177} \mathrm{Lu}\right] \mathrm{Lu}$-DOTA-TATE was associated with a $79 \%$ reduction in the risk of progression or death compared to the control arm. PFS was significantly higher in the PRRT arm, and the interim analysis even suggested longer OS; furthermore, overall toxicity was limited [131]. Although this study included only patients with midgut NETs, the subsequent approval of $\left[{ }^{177} \mathrm{Lu}\right] \mathrm{Lu}-\mathrm{DOTA}-\mathrm{TATE}$ was also extended to pancreatic NETs following the publication of the Erasmus study, reporting the safety and efficacy of $\left[{ }^{177} \mathrm{Lu}\right] \mathrm{Lu}$-DOTA-TATE in a large population of patients $(n=610)$. Among the subgroup of 443 patients analyzed for efficacy and survival, patients with primary pancreatic NETs $(n=133)$ had the longest OS (71 months) [132].

$\left[{ }^{177} \mathrm{Lu}\right] \mathrm{Lu}-\mathrm{DOTA}-\mathrm{TATE}$ is now approved [130] for the treatment of unresectable or metastatic, progressive, well-differentiated (G1 and G2), SSTR-positive GEP NETs in adults in Europe and the United States, and for bronchial NENs in the United States. Recently, the NETTER-1 study's final findings (at 5 years after the last patient was randomized) were presented during the 2021 American Society of Clinical Oncology (ASCO) annual meeting. $\left[{ }^{177} \mathrm{Lu}\right] \mathrm{Lu}$-DOTA-TATE treatment was associated with a clinically and statistically significant improvement in PFS (HR: $0.18, p<0.0001$ ). Interestingly, although longer OS was observed in the treated arm, there was no statistically significant difference in the median OS between the [ $\left.{ }^{177} \mathrm{Lu}\right] \mathrm{Lu}-\mathrm{DOTA}-\mathrm{TATE}$ arm (48.0 months; 95\% CI: 37.4-55.2) and the control arm (36.3 months, 95\% CI: 25.9-51.7). This can likely be explained by the high rate $(36 \%)$ of crossover of progressing patients from the control arm to the PRRT arm. No new safety signals emerged during the 5-year long-term follow-up (in particular, no new cases of MDS or acute leukemia were reported in the long-term follow-up) [131].

Collecting the evidence gathered so far, PRRT should be considered as a systemic, effective, and safe treatment option, and has been included in the therapeutic algorithms of the main scientific societies. However, there are still many issues to be clarified regarding the most efficient positioning of PRRT in the therapeutic algorithm sequence, the eligibility criteria for PRRT, treatment scheduling, dosimetry estimation, and response assessment criteria.

\subsection{PRRT: Impact on Quality of Life}

NET patients' symptoms can be related to tumor growth as well as hormone production. The carcinoid syndrome (CS) is characterized by skin flushing, diarrhea, abdominal pain, fast heart rate, and bronchospasm. Especially in severe CS, symptomatic control can be challenging; thus, quality of life (QoL) may be significantly affected by symptoms related to tumor growth, as well as by hormone production [133]. Somatostatin analogues are typically used for the control of tumor growth and hormonal symptoms [134]. To date, the effectiveness of PRRT in the treatment of advanced GEP NETs in terms of controlling the CS and improving QoL is supported by various published trials, as well as by clinical experience [131,135-140]. In a study that evaluated the QoL of 265 patients, the authors found that global health status (GHS), QoL, Karnofsky performance score (KPS), and symptoms significantly improved after PRRT; moreover, there was no significant decrease in QoL in patients who had no symptoms before therapy. In patients who had suboptimal scores for GHS/QOL or symptoms before therapy, a clinically significant improvement was reported [135]. Moreover, in an analysis from the NETTER-1 phase III study, the impact of $\left.{ }^{[177} \mathrm{Lu}\right] \mathrm{Lu}$-DOTA-TATE treatment on time to deterioration (TTD) in health-related QoL was assessed; in addition to improving PFS, $\left[{ }^{177} \mathrm{Lu}\right] \mathrm{Lu}$-DOTA-TATE provided a significant $\mathrm{QoL}$ benefit for patients with progressive midgut NETs as compared to high-dose octreotide LAR [136]. In particular, the authors reported statistically significant reductions from baseline in the mean number of days with all three core symptoms of patients with progressive 
midgut NETs (i.e., abdominal pain, diarrhea, and flushing), as compared with high-dose octreotide LAR treatment. TTD was significantly longer in the [ $\left.{ }^{177} \mathrm{Lu}\right] \mathrm{Lu}-\mathrm{DOTA}-\mathrm{TATE}$ arm versus the control arm (for GHS, physical functioning, role functioning, fatigue, pain, diarrhea, disease-related worries, and body image). Differences in median TTD were clinically significant in several domains: 28.8 months versus 6.1 months for GHS, and 25.2 months versus 11.5 months for physical functioning [136]. In a more limited cohort of 22 patients with refractory CS syndrome and radiologically stable or newly diagnosed disease, PRRT effectively reduced diarrhea and flushing. The authors concluded that PRRT should be considered for symptomatic treatment of CS insufficiently controlled with somatostatin analogues [141].

\subsection{PRRT: Eligibility and Contraindications}

The first guidelines on the clinical use of PRRT were published in 2013 thanks to a joint effort of the EANM, International Atomic Energy Agency, and Society of Nuclear Medicine and Molecular Imaging, followed by the ENETS Consensus Guidelines (2017) and the North American Neuroendocrine Tumor Society (NANETS) Consensus Statement on Patient Selection for PRRT (2020) [8,142].

All guidelines agree on the need for multidisciplinary discussion of each case in order to evaluate PRRT eligibility. Inoperable/metastatic well-differentiated G1-G2 NETs are the best candidate patients. Currently, PRRT is offered as a second-line treatment, after failure of first-line treatment with somatostatin analogues, in patients with a KPS $>50$ and expected survival $>3$ months. In all cases, significant SSTR expression should be demonstrated by SSTR imaging (the tumor uptake should be at least as high as normal liver uptake: Krenning score $\geq 2$ ) [49].

As a result of the publication of the NETTER-1 phase III study, PRRT with [ $\left.{ }^{177} \mathrm{Lu}\right] \mathrm{Lu}-$ DOTA-TATE is currently approved for adult patients with unresectable or metastatic, progressive, well-differentiated (G1 and G2), SSTR-positive GEP NETs [131]. Currently, GEP NET patients can be treated with PRRT as a second-line treatment, after the failure of first-line somatostatin analogues.

PRRT's absolute contraindications include pregnancy, hypersensitivity to the active substance or to any of the excipients contained in the radiopharmaceutical, severe acute concomitant illnesses (e.g., severe cardiac or liver impairment), and severe unmanageable psychiatric disorders. Breastfeeding should be discontinued before PRRT. Severely compromised renal function represents a relative contraindication [98]; the ENETS recommends that patients should have a creatinine clearance of $\geq 50 \mathrm{~mL} / \mathrm{min}$ [8], while the NANETS suggests that a creatinine clearance of $\geq 30 \mathrm{~mL} / \mathrm{min}$ is sufficient [142]. As mentioned above, aminoacidic infusion is recommended because it notably reduces the radiopharmaceutical's renal uptake; renal toxicity with $\left[{ }^{177} \mathrm{Lu}\right] \mathrm{Lu}$-DOTA-TATE is negligible when prophylactic amino acids are used, even in patients with a glomerular filtration rate $<50 \mathrm{~mL} / \mathrm{min}$. Moreover, co-infusions of arginine/lysine result in substantially lower rates of nausea/vomiting compared with commercial amino acid formulations designed for parenteral nutrition [143]. Literature data are also in favor of extending both the amino acid solution infusion time and the amino acid protection to over 2 days, in order to further reduce renal toxicity.

Sufficient bone marrow reserves are required (grade 1-2 hematological toxicity is usually accepted). An accurate pre-administration evaluation should be carried out in order to select patients at higher risk of renal or bone marrow toxicity; at least 2-4 weeks and directly before administration of each $\left[{ }^{177} \mathrm{LuLu}\right]$-DOTA-TATE dose, the liver and kidney function as well as hematological parameters must be checked. When dose-modifying toxicity occurs, either prolongation of the treatment interval (up to 16 weeks) or treatment discontinuation may become necessary.

Among the relative contraindications, the ENETS guidelines indicate the presence of mismatched lesions on $\left[{ }^{18} \mathrm{~F}\right] \mathrm{FDG}$ and SSTR PET/CT $\left(\left[{ }^{18} \mathrm{~F}\right] \mathrm{FDG}\right.$-positive and $\left[{ }^{68} \mathrm{Ga}\right] \mathrm{Ga}-$ DOTA-peptide-negative), as well as cases with low SSTR expression or mesenteric disease. 
Although $\left[{ }^{18} \mathrm{~F}\right] \mathrm{FDG}$ PET/CT is not part of the standard pre-PRRT protocol, it is well known that a lower response to PRRT is expected in patients with matched $\left(\left[{ }^{18} \mathrm{~F}\right] \mathrm{FDG}-\right.$ and $\left[{ }^{68} \mathrm{Ga}\right] \mathrm{Ga}$-DOTA-peptide-positive) lesions, representing a contraindication to PRRT alone when lesions are mismatched.

In the recent EANM Focus 3, the use of $\left[{ }^{18} \mathrm{~F}\right] \mathrm{FDG}$ PET/CT before PRRT was recommended in the event of non-resectable/disseminated G2 or G3 NETs, in order to exclude mismatched lesions, or as a prognostic factor. The possibility of treating patients with G3 NETs has been suggested by several positive experiences [40,50,51]. However, current international guidelines provide different indications; the ENETS guidelines state that PRRT may be considered for G3 NETs (although further data are needed) and even NECs with SSTR-expressing disease [8], while the NANET guidelines emphasize the limited data on PRRT in these subgroups [142]. It is also worth mentioning that current evidence suggests that PRRT may potentially be a superior first-line therapeutic option for G3 NET patients with $\mathrm{Ki}-67 \leq 55 \%$, as compared to platinum-based chemotherapy (providing high SSTR expression with no discordant FDG-avid lesions) [144].

Further data are certainly needed in order to determine the real potential benefit of this treatment option in G3 NET patients; the results of the ongoing NETTER-2 study (evaluating PRRT as a first-line treatment in G2 and G3 NETs) will likely help elucidate this issue (https: / / clinicaltrials.gov / ct2/ show / NCT03972488 accessed on 6 November 2021).

Another aspect to consider in the selection of patients is the presence of extensive peritoneal carcinomatosis (PC), for the potential risk of radiation-induced bowel obstruction [142]. This is another area of debate; the NANETS guidelines indicate that patients with bulky mesenteric tumors and PC are potentially at higher risk for PRRT, while the ENETS guidelines do not address this topic. Some literature data suggest that PRRT should be adopted with caution in GEP NETs with diffuse PC. A retrospective, single-center analysis performed in 135 GEP NENs with diffuse PC treated with PRRT showed peritoneal progression in $37.5 \%$ of cases, and bowel obstruction or ascites in $28.1 \%$ [145]. One study recently reported a bowel obstruction rate of $5 \%$ among patients with baseline mesenteric or peritoneal disease [146]. Premedication with low-dose steroids started after PRRT and continued for 2-4 weeks after therapy has been proposed to prevent complications in patients with PC $[142,145]$.

The final indication for PRRT needs to be discussed in a multidisciplinary setting (oncologists, nuclear medicine physicians, radiologists, endocrinologists, surgeons, gastroenterologists, endoscopists, etc.), while also considering the other available treatment options (e.g., defining the most appropriate treatment sequence), as well as various factors that are known to potentially affect PRRT response (e.g., performance status, primary tumor site, previous treatments, biomarkers, grading, tumor burden, $\left[{ }^{18} \mathrm{~F}\right] \mathrm{FDG}$ and $\left[{ }^{68} \mathrm{Ga}\right] \mathrm{Ga}-$ DOTA peptides PET/CT uptake: match/mismatch) [62,64,112,138,147-150].

\subsection{Personalized Dose or Fixed-Dose Scheme?}

The possibility of personalizing the treatment scheme for each patient would be desirable. From a technical point of view, dosimetry is feasible; the main focus of dosimetry is to improve efficacy by sparing at-risk organs (reducing toxicity), and to optimize the dose delivered to the tumor. Since ${ }^{90} \mathrm{Y}$ does not emit suitable $\gamma$-rays, imaging after administration is difficult; on the other hand, ${ }^{177} \mathrm{Lu}$ emits low-energy $\gamma$-rays that allow dosimetric evaluation between cycles.

As mentioned above, the kidneys and the bone marrow represent critical targets of long-term PRRT toxicity. However, it was not possible to identify a definitive threshold for the risk of developing nephrotoxicity or hematotoxicity. In clinical practice, a threshold of $23 \mathrm{~Gy}$, derived from radiation therapy studies, is generally used for kidneys, and a threshold of $2 \mathrm{~Gy}$, adapted from radioiodine therapy, is used for bone marrow. However, there is no clear evidence that these cutoffs are optimal for PRRT [151-154].

Although the results of the final analysis of the NETTER-1 study indicate that PRRT is safe and effective, and rarely causes serious toxicity [155], there is evidence that dosimetric 
evaluation can play an important role-especially in patients with risk factors for renal or hematological toxicity, or those presenting with comorbidities $[63,120,121]$. Moreover, several studies have shown that additional PRRT cycles (salvage therapy setting) or retreatments can be safely performed following dosimetric estimations [156-159].

Dosimetric evaluation was previously focused mainly on normal organs (so as to limit side effects), but in recent years it has been used to better understand the correlation between tumors' absorbed dose and tumor response. For pancreatic neuroendocrine tumors, a significant correlation between tumor dose and tumor shrinkage was reported [160], which was however not confirmed in 25 patients with small intestine NENs [161].

Despite the efforts and the numerous publications to further improve PRRT by using dosimetry [154], a recent survey in European centers applying radionuclide therapies has shown that dosimetry is rarely or never used in more than half of centers; moreover, its results barely influence treatment [162]. One of the reasons is that dosimetry is time-consuming, labor-intensive, expensive, and costs patient time (multiple acquisitions are required).

Nevertheless, each country has already adopted or will have to adopt the forthcoming European Council Directive 2013/59/Euratom that, in article 56, mandates the use of dosimetry-based treatment planning and verification of the absorbed doses delivered, taking into account that doses to non-target volumes and tissues should be as low as reasonably achievable and consistent with the intended radiotherapeutic purpose of the exposure. In view of the Council Directive (2013/59/Euratom), there is a need to increase the possibilities and benefits of a higher degree of implementation of dosimetry, and this implies having more practical, robust, and standardized dosimetry methods for wider clinical application.

\subsection{New Trends and Future Perspectives of PRRT for the Treatment of NETs}

A higher risk of disease progression on PRRT has been observed in NET patients with lesions $\geq 3 \mathrm{~cm}$ in size or that show $\left[{ }^{18} \mathrm{~F}\right] \mathrm{FDG}$ positivity $[64,163]$, suggesting the need to improve PRRT's debulking capability as well as its efficacy in some patient categories [164]. Ongoing studies are exploring different strategies to improve outcomes on PRRT of patients with NENs, such as using different peptides, radionuclides, and carriers, by combining PRRT with radiosensitizers, or by optimizing the treatment sequence.

\subsubsection{Improving PRRT: Investigational Peptides, Radionuclides, and Carriers}

$\left[{ }^{177} \mathrm{Lu}\right] \mathrm{Lu}$-edotreotide (DOTA-TOC) is an investigational radiolabeled somatostatin analog that showed a favorable safety profile and promising efficacy in a retrospective study, obtaining a median PFS of 34.5 months $[165,166]$. The COMPETE study is an ongoing multicenter randomized controlled phase III trial of $\left[{ }^{177} \mathrm{Lu}\right] \mathrm{Lu}$-edotreotide versus everolimus in patients with progressing advanced GEP NETs (expected $n=300$ ), with PFS as the primary endpoint (NCT03049189).

As mentioned above, SSTR antagonists may offer advantages over currently employed agonists $[89,93]$. The safety of satoreotide tetraxetan (formerly known as $\left[{ }^{177} \mathrm{Lu}\right] \mathrm{Lu}-\mathrm{DOTA}-$ JR11) - an SSTR antagonist - was investigated in a phase I clinical trial in 40 patients with well-differentiated NETs, who received two cycles of the investigational agent 3 months apart (NCT02609737) [167]. After 20 patients were enrolled (with 6 patients receiving one cycle and 14 receiving two cycles), grade 4 myelosuppression was observed in $57.1 \%$ of cases after cycle two, so that a protocol amendment was needed to limit the bone marrow dose to 1 Gy and reduce the dose of cycle 2 by $50 \%$. Preliminary efficacy data reported an ORR of $45 \%$ and a median PFS of 21.0 months [167].

Because of their higher linear energy transfer, $\alpha$-emitting radionuclides are an attractive agent to improve PRRT efficacy in NETs, despite the potential risk of the release of daughter radionuclides from the chelator, which can have a long half-life and, thus, result in increased rates of severe toxicity. Actinium-225 [ $\left.{ }^{225} \mathrm{Ac}\right]$, bismuth-213 ([ $\left.\left.{ }^{213} \mathrm{Bi}\right]\right)$, and lead-212 $\left(\left[{ }^{212} \mathrm{~Pb}\right]\right)$ are three experimental $\alpha$-emitters that have been shown to be active 
in patients with NENs refractory to ${ }^{90} \mathrm{Y}$ - or ${ }^{177}$ Lu-based PRRT [168-170]. In particular, a phase I trial of [ $\left.{ }^{212} \mathrm{~Pb}\right] \mathrm{Pb}-\mathrm{DOTA}-\mathrm{TATE}$ in treatment-naïve patients with NETs is ongoing (NCT03466216) [170].

The development of novel carriers could improve PRRT efficacy by optimizing pharmacokinetics and dosimetry. A phase I study of $\left[{ }^{177} \mathrm{Lu}\right] \mathrm{Lu}$-DOTA-EB-TATE in patients with NETs reported increased circulation time and tumor uptake compared to $\left[{ }^{177} \mathrm{Lu}\right] \mathrm{Lu}-\mathrm{DOTA}-$ TATE, but also increased kidney and bone marrow dose delivery (NCT03478358) [171].

\subsubsection{Combining PRRT: Chemotherapy and Other Radiosensitizers}

To increase the damage caused by radiation to tumor cells and increase their killing, different radiosensitizers can be administered concomitantly to PRRT. One way to achieve this aim — and the most extensively explored way—is to combine PRRT with chemotherapy, such as a fluoropyrimidine, namely, 5-fluorourcil (5FU) or capecitabine (CAP) and/or temozolomide (TEM) $[164,172]$. Peptide receptor chemo-radionuclide therapy (PRCRT) in patients with well-differentiated GEP NETs treated within early-phase clinical trials provided ORRs as high as $24-53 \%$ [173-175], which also exceeded $80 \%$ in the subgroup of patients with pancreatic NETs receiving PRCRT with TEM-likely because of the role of MGMT (O(6)-methylguanine-DNA methyltransferase) promoter methylation in these patients [176]. In these studies, PRCRT was safe and its toxicity was manageable, with mainly grade 2 and grade 3 subacute hematological toxicity and nausea. The CONTROL NETS study is an ongoing randomized non-comparative phase II trial of the combination of CAPTEM and [ ${ }^{177} \mathrm{Lu}$ ]Lu-DOTA-TATE, or either treatment alone, in patients with welldifferentiated G1-2 pancreatic and midgut NETs (NCT02358356) [177]. Preliminary data on small bowel NET $(n=47)$ patients showed a 15-month PFS rate - the primary endpoint-of $90 \%$ and $92 \%$ and an ORR of $31 \%$ vs. $15 \%$ in the PRCRT arm $(n=33)$ and in the PRRT arm $(n=14)$, respectively. In the cohort of patients with pancreatic NETs $(n=28)$, the 12-month PFS rate- the primary endpoint-was $76 \%$ and $67 \%$ with an ORR of $68 \%$ vs. $33 \%$ in the PRCRT arm $(n=19)$ and in the CAPTEM arm $(n=9)$, respectively. Despite similar efficacy in terms of PFS, PRCRT yielded numerically higher ORR alongside greater toxicity, mainly affecting the bone marrow. PRCRT can also be a useful strategy in the specific setting of patients with $\left[{ }^{18} \mathrm{~F}\right] \mathrm{FDG}$-positive NENs, as there are data showing that PRCRT with 5FU is feasible, active (with an ORR of 30\%), and tolerable, as grade $3-4$ adverse events were observed in approximately $8 \%$ of the 52 patients with $\left[{ }^{18} \mathrm{~F}\right] \mathrm{FDG}$-avid NENs of mostly GEP origin included in a retrospective analysis [178].

The efficacy of PRRT in patients with well-differentiated NETs with a high proliferation index (G2 NET with Ki-67 > 10\% and G3 NET) is still unclear. To clarify the role of PRRT in this setting, the NETTER-2 study - a randomized open-label multicenter phase III trial of $\left[{ }^{177} \mathrm{Lu}\right] \mathrm{Lu}$-DOTA-TATE compared to high-dose octreotide LAR in patients with G2 and G3 advanced GEP NETs—is ongoing (NCT03972488).

The COMPOSE study - a prospective randomized controlled open-label multicenter phase III trial of [ $\left.{ }^{177} \mathrm{Lu}\right] \mathrm{Lu}$-edotreotide compared to standard of care (including everolimus and chemotherapy) in the same population-has a similar objective (NCT04919226).

Some retrospective series have reported the use of PRCRT (with 5FU, CAP, or CAPTEM) in cohorts that also included patients with G3 NENs, with an ORR of 30-47\% $[137,179,180]$. Nevertheless, the rate of patients presenting disease progression as the best response was high, ranging from $20 \%$ to $26 \%$, suggesting either a need for careful patient selection, or that the intrinsic aggressiveness of G3 NETs makes PRRT or PRCRT unsuitable for these patients.

Poly(ADP-ribose) polymerase inhibitors (PARPis) are widely used, alone or in combination, in different tumor types, because they inhibit homologous recombination-a pathway of the DNA damage response repair machinery-and result in cell death under certain conditions [181]. The rationale of using PARPis as radiosensitizers lies in the fact that tumor cells are not able to repair the DNA single-strand break induced by $\left[{ }^{177} \mathrm{Lu}\right] \mathrm{Lu}-\mathrm{DOTA}-\mathrm{TATE}$ in the presence of PARPis, resulting in DNA double-strand break 
and cell death, as also shown in preclinical NET models [182]. Olaparib, a PARPi, will be administered twice daily from 2 days prior to the start to 4 weeks after the end of $\left[{ }^{177} \mathrm{Lu}\right] \mathrm{Lu}-$ DOTA-TATE treatment in patients with progressive GEP NETs who have not previously received PRRT in a phase I/II trial (NCT04086485). Similarly, radionuclide reductase is a rate-limiting enzyme in DNA synthesis and repair, and its inhibition might sensitize NET cells to radiation damage [183]. A phase I study of [ ${ }^{177} \mathrm{Lu}$ ]Lu-DOTA-TATE and triapine-a radionuclide reductase inhibitor-in PRRT-naïve patients with well-differentiated GEP NETs is ongoing [184].

\subsubsection{The Place Where PRRT Belongs: Concepts of Sequencing}

There is no current consensus on the sequencing of approved therapies, particularly with respect to PRRT. Available evidence is mostly derived from retrospective and, therefore, potentially biased series $[8,74,185]$. A recent retrospective multicenter Italian study showed that $\left[{ }^{177} \mathrm{Lu}\right] \mathrm{Lu}$-DOTA-TATE, as well as non-conventional-dose somatostatin analogues [186], are better tolerated than chemotherapy or everolimus, with no significant difference in PFS [187]. Because a recent network meta-analysis showed that $\left[{ }^{177} \mathrm{Lu}\right] \mathrm{Lu}-$ DOTA-TATE had the highest probability of being associated with the longest PFS as compared to other approved treatments [188], it is not surprising that ongoing studies-namely, the NETTER-2 (NCT03972488) and COMPETE trials (NCT03049189)-aim at first-line positioning of PRRT. Nevertheless, shifting PRRT to earlier in the treatment algorithm for patients with NETs is associated with poorer tolerance of subsequent treatments, such as everolimus [189], or might not be associated with improved outcomes, e.g., in patients with pancreatic NETs [190]. As surgery is also acknowledged to be the only potentially curative treatment for NET patients in the metastatic setting, some patients with marginally unresectable NETs can benefit from neoadjuvant treatment and be considered as surgical candidates. PRRT's role in the neoadjuvant setting has been reported in a retrospective study, with the interesting collateral finding of a reduced incidence of subsequent liver metastasis. To confirm these findings, a prospective phase II trial of neoadjuvant PRRT with $\left[{ }^{177} \mathrm{Lu}\right] \mathrm{Lu}$-DOTA-TATE followed by surgery for patients with resectable pancreatic NETs is currently ongoing (NCT04385992). The feasibility of PRRT re-treatment presents an appealing opportunity in NET patients who initially respond and then experience disease progression, given the long-term benefit in terms of PFS and the good subjective patient tolerance. PRRT re-treatment is not currently recommended by guidelines, but there are some retrospective reports about its safety and feasibility, potentially leading to PFS of 14-22 months [156,191].

\section{Conclusions}

NENs are rare and heterogeneous cancers that can be managed using the theranostic principle. From the diagnostic perspective, SSTR PET/CT is the gold standard modality for imaging of NETs (i.e., identification of primary lesion, disease extension, selection for PRRT). Intra-patient and interlesional SSTR heterogeneity (e.g., metastases may differ from the primary tumor; each metastasis may derive from a different clone, with variable SSTR expression) may require additional $\left[{ }^{18} \mathrm{~F}\right] \mathrm{FDG}$ PET/CT to assess the glycolytic metabolism, impacting both management and prognosis. On the therapeutic side, PRRT should be considered as a systemic, effective, and safe treatment option, and is included in the therapeutic algorithms of the main scientific societies. The final indication for PRRT needs to be discussed at a multidisciplinary level, while also considering the other available treatment options as well as various factors that are known to potentially reduce its efficacy (e.g., performance status, primary tumor site, previous treatments, biomarkers, grading, tumor burden, and $\left[{ }^{18} \mathrm{~F}\right] \mathrm{FDG}$ and $\left[{ }^{68} \mathrm{Ga}\right] \mathrm{Ga}-\mathrm{DOTA}$ peptides PET/CT uptake: match/mismatch). Ongoing studies are focused on the optimal treatment sequence, a better definition of PRRT selection criteria, strategies to reduce treatment-induced toxicity, and novel radiopharmaceuticals (e.g., fluorinated analogues, antagonists). 
Author Contributions: Conceptualization, V.A. and L.Z.; methodology, V.A. and L.Z.; writingoriginal draft preparation, V.A., L.Z., A.F., G.L., G.A., E.F., D.C., A.V. and S.F.; writing-review and editing, V.A., L.Z., A.F., G.L., G.A., E.F., D.C., A.V. and S.F.; visualization, V.A. and L.Z.; supervision, V.A. and L.Z. All authors have read and agreed to the published version of the manuscript.

Funding: This review received no external funding.

Conflicts of Interest: Giulia Argalia, Emilia Fortunati, Giuseppe Lamberti, and Davide Campana declare no conflict of interest. Valentina Ambrosini reports personal fees from ESMIT, EANM/ESMO, and AAA outside the submitted work, and is a member of the ENETS advisory board, ESMO faculty staff for NETs, the EANM Oncology and Theranostic Committee, and the scientific board of ITANET. Stefano Fanti reports, outside the submitted work, personal honoraria from Novartis (and personal fees from ANMI, Astellas, Bayer, Blue Earth Diagnostics, GE Healthcare, Jenssen, and Sofie Biosciences, along with non-financial support from AAA, Bayer, GE Healthcare, Curium, Tema Sinergie, Sanofi, and Telix). Lucia Zanoni reports, outside the submitted work, personal fees from Springer (as a book editor). Annibale Versari reports honoraria for advisory roles from Novartis and Advanced Accelerator Applications. Angelina Filice reports personal fees from AAA, Novartis, Bayer, and AstraZeneca outside the submitted work.

\section{References}

1. Yamaguchi, T.; Fujimori, T.; Tomita, S.; Ichikawa, K.; Mitomi, H.; Ohno, K.; Shida, Y.; Kato, H. Clinical validation of the gastrointestinal NET grading system: Ki67 index criteria of the WHO 2010 classification is appropriate to predict metastasis or recurrence. Diagn. Pathol. 2013, 8, 65. [CrossRef] [PubMed]

2. Gill, A.J. Why did they change that? Practical implications of the evolving classification of neuroendocrine tumours of the gastrointestinal tract. Histopathology 2021, 78, 162-170. [CrossRef] [PubMed]

3. Dahdaleh, F.S.; Lorenzen, A.; Rajput, M.; Carr, J.C.; Liao, J.; Menda, Y.; O’Dorisio, T.M.; Howe, J.R. The value of preoperative imaging in small bowel neuroendocrine tumors. Ann. Surg. Oncol. 2013, 20, 1912-1917. [CrossRef] [PubMed]

4. Bushnell, D.L.; Baum, R.P. Standard Imaging Techniques for Neuroendocrine Tumors. Endocrinol. Metab. Clin. N. Am. 2011, 40, 153-162. [CrossRef]

5. Guo, C.; Zhuge, X.; Chen, X.; Wang, Z.; Xiao, W.; Wang, Q. Value of diffusion-weighted magnetic resonance imaging in predicting World Health Organization grade in G1/G2 pancreatic neuroendocrine tumors. Oncol. Lett. 2017, 13, 4141-4146. [CrossRef] [PubMed]

6. Sundin, A.; Arnold, R.; Baudin, E.; Cwikla, J.B.; Eriksson, B.; Fanti, S.; Fazio, N.; Giammarile, F.; Hicks, R.J.; Kjaer, A.; et al. ENETS consensus guidelines for the standards of care in neuroendocrine tumors: Radiological, nuclear medicine \& hybrid imaging. Neuroendocrinology 2017, 105, 212-244. [CrossRef] [PubMed]

7. Kwekkeboom, D.J.; Krenning, E.P.; Lebtahi, R.; Komminoth, P.; Kos-Kudla, B.; Herder, W.W.D.; Plockinger, U. Mallorca consensus conference participants; European neuroendocrine tumor society ENETS consensus guidelines for the standards of care in neuroendocrine tumors: Peptide receptor radionuclide therapy with radiolabeled somatostatin analogs. Neuroendocrinology 2009, 90, 220-226. [CrossRef] [PubMed]

8. Hicks, R.J.; Kwekkeboom, D.J.; Krenning, E.; Bodei, L.; Grozinsky-Glasberg, S.; Arnold, R.; Borbath, I.; Cwikla, J.B.; Toumpanakis, C.; Kaltsas, G.; et al. ENETS Consensus Guidelines for the Standards of Care in Neuroendocrine Neoplasms: Peptide Receptor Radionuclide Therapy with Radiolabelled Somatostatin Analogues. Neuroendocrinology 2017, 105, 295-309. [CrossRef]

9. Gabriel, M.; Decristoforo, C.; Kendler, D.; Dobrozemsky, G.; Heute, D.; Uprimny, C.; Kovacs, P.; Von Guggenberg, E.; Bale, R.; Virgolini, I.J. 68Ga-DOTA-Tyr3-Octreotide PET in neuroendocrine tumors: Comparison with somatostatin receptor scintigraphy and CT. J. Nucl. Med. 2007, 48, 508-518. [CrossRef]

10. Barrio, M.; Czernin, J.; Fanti, S.; Ambrosini, V.; Binse, I.; Du, L.; Eiber, M.; Herrmann, K.; Fendler, W.P. The impact of somatostatin receptor-directed pet/ct on the management of patients with neuroendocrine tumor: A systematic review and meta-analysis. J. Nucl. Med. 2017, 58, 756-761. [CrossRef]

11. Hennrich, U.; Benesova, M. [68Ga]Ga-DOTA-TOC: The first FDA-approved 68Ga-radiopharmaceutical for PET imaging. Pharmaceuticals 2020, 13, 38. [CrossRef] [PubMed]

12. Yu, J.; Cao, F.; Zhao, X.; Xie, Q.; Lu, M.; Li, J.; Yang, Z.; Sun, Y. Correlation and comparison of somatostatin receptor type 2 immunohistochemical scoring systems with 68Ga-DOTATATE positron emission tomography/computed tomography imaging in gastroenteropancreatic neuroendocrine neoplasms. NEN 2021, Online ahead of print. [CrossRef]

13. Putzer, D.; Kroiss, A.; Waitz, D.; Gabriel, M.; Traub-Weidinger, T.; Uprimny, C.; von Guggenberg, E.; Decristoforo, C.; Warwitz, B.; Widmann, G.; et al. Somatostatin receptor PET in neuroendocrine tumours: 68Ga-DOTA0,tyr3-octreotide versus 68Ga-DOTA0lanreotide. Eur. J. Nucl. Med. Mol. Imaging 2013, 40, 364-372. [CrossRef] [PubMed]

14. Bozkurt, M.F.; Virgolini, I.; Balogova, S.; Beheshti, M.; Rubello, D.; Decristoforo, C.; Ambrosini, V.; Kjaer, A.; Delgado-Bolton, R.; Kunikowska, J.; et al. Guideline for PET/CT imaging of neuroendocrine neoplasms with 68Ga-DOTA-Conjugated somatostatin receptor targeting peptides and 18F-DOPA. Eur. J. Nucl. Med. Mol. Imaging 2017, 44, 1588-1601. [CrossRef]

15. Start-Enets.Org. Available online: https://www.enets.org/ (accessed on 31 December 2021).

16. Reubi, J.C. Peptide receptors as molecular targets for cancer diagnosis and therapy. Endocr. Rev. 2003, 24, 389-427. [CrossRef] [PubMed] 
17. Hope, T.A.; Bergsland, E.K.; Bozkurt, M.F.; Graham, M.; Heaney, A.P.; Herrmann, K.; Howe, J.R.; Kulke, M.H.; Kunz, P.L.; Mailman, J.; et al. Appropriate use criteria for somatostatin receptor PET imaging in neuroendocrine tumors. J. Nucl. Med. 2018, 59, 66-74. [CrossRef]

18. Kunikowska, J.; Ambrosini, V.; Herrmann, K. EANM focus 3: The international conference on molecular imaging and theranostics in neuroendocrine tumours-the consensus in a nutshell. Eur. J. Nucl. Med. Mol. Imaging 2021, 48, 1276-1277. [CrossRef] [PubMed]

19. Ambrosini, V.; Kunikowska, J.; Baudin, E.; Bodei, L.; Bouvier, C.; Capdevila, J.; Cremonesi, M.; Herder, W.W.d.; Dromain, C.; Falconi, M.; et al. Consensus on molecular imaging and theranostics in neuroendocrine neoplasms. Eur. J. Cancer 2021, 146, 56-73. [CrossRef]

20. Virgolini, I.; Ambrosini, V.; Bomanji, J.B.; Baum, R.P.; Fanti, S.; Gabriel, M.; Papathanasiou, N.D.; Pepe, G.; Oyen, W.; Cristoforo, C.D.; et al. Procedure guidelines for PET/CT tumour imaging with 68Ga-DOTA-conjugated peptides: 68Ga-DOTA-TOC, 68Ga-DOTA-NOC, 68Ga-DOTA-TATE. Eur. J. Nucl. Med. Mol. Imaging 2010, 37, 2004-2010. [CrossRef] [PubMed]

21. Ambrosini, V.; Campana, D.; Tomassetti, P.; Fanti, S. ${ }^{6}$ Ga-Labelled peptides for diagnosis of gastroenteropancreatic NET. Eur. J. Nucl. Med. Mol. Imaging 2012, 39 (Suppl. 1), S52-S60. [CrossRef]

22. Srirajaskanthan, R.; Kayani, I.; Quigley, A.M.; Soh, J.; Caplin, M.E.; Bomanji, J. The role of 68Ga-DOTATATE PET in patients with neuroendocrine tumors and negative or equivocal findings on 111In-DTPA-Octreotide scintigraphy. J. Nucl. Med. 2010, 51, 875-882. [CrossRef] [PubMed]

23. Skoura, E.; Michopoulou, S.; Mohmaduvesh, M.; Panagiotidis, E.; Harbi, M.A.; Toumpanakis, C.; Almukhailed, O.; Kayani, I.; Syed, R.; Navalkissoor, S.; et al. The impact of 68Ga-DOTATATE PET/CT imaging on management of patients with neuroendocrine tumors: Experience from a national referral center in the united kingdom. J. Nucl. Med. 2016, 57, 34-40. [CrossRef] [PubMed]

24. Ambrosini, V.; Nanni, C.; Zompatori, M.; Campana, D.; Tomassetti, P.; Castellucci, P.; Allegri, V.; Rubello, D.; Montini, G.; Franchi, R.; et al. (68)Ga-DOTA-NOC PET/CT in comparison with CT for the detection of bone metastasis in patients with neuroendocrine tumours. Eur. J. Nucl. Med. Mol. Imaging 2010, 37, 722-727. [CrossRef]

25. Putzer, D.; Gabriel, M.; Henninger, B.; Kendler, D.; Uprimny, C.; Dobrozemsky, G.; Decristoforo, C.; Bale, R.J.; Jaschke, W.; Virgolini, I.J. Bone metastases in patients with neuroendocrine tumor: 68Ga-DOTA-Tyr3-Octreotide PET in comparison to CT and bone scintigraphy. J. Nucl. Med. 2009, 50, 1214-1221. [CrossRef] [PubMed]

26. Fendler, W.P.; Barrio, M.; Spick, C.; Allen-Auerbach, M.; Ambrosini, V.; Benz, M.; Bluemel, C.; Grewal, R.K.; Lapa, C.; Miederer, M.; et al. 68Ga-DOTATATE PET/CT interobserver agreement for neuroendocrine tumor assessment: Results of a prospective study on 50 patients. J. Nucl. Med. 2017, 58, 307-311. [CrossRef] [PubMed]

27. Ambrosini, V.; Campana, D.; Bodei, L.; Nanni, C.; Castellucci, P.; Allegri, V.; Montini, G.C.; Tomassetti, P.; Paganelli, G.; Fanti, S. 68Ga-DOTANOC PET/CT clinical impact in patients with neuroendocrine tumors. J. Nucl. Med. 2010, 51, 669-673. [CrossRef] [PubMed]

28. Treglia, G.; Sadeghi, R.; Giovinazzo, F.; Galiandro, F.; Annunziata, S.; Muoio, B.; Kroiss, A.S. PET with different radiopharmaceuticals in neuroendocrine neoplasms: An umbrella review of published meta-analyses. Cancers 2021, 13, 5172. [CrossRef] [PubMed]

29. Singh, S.; Poon, R.; Wong, R.; Metser, U. 68Ga PET imaging in patients with neuroendocrine tumors: A systematic review and meta-analysis. Clin. Nucl. Med. 2018, 43, 802-810. [CrossRef] [PubMed]

30. Treglia, G.; Castaldi, P.; Rindi, G.; Giordano, A.; Rufini, V. Diagnostic performance of gallium-68 somatostatin receptor PET and PET/CT in patients with thoracic and gastroenteropancreatic neuroendocrine tumours: A meta-analysis. Endocrine 2012, 42, 80-87. [CrossRef] [PubMed]

31. Geijer, H.; Breimer, L.H. Somatostatin receptor pet/ct in neuroendocrine tumours: Update on systematic review and meta-analysis. Eur. J. Nucl. Med. Mol. Imaging 2013, 40, 1770-1780. [CrossRef]

32. Yang, J.; Kan, Y.; Ge, B.H.; Yuan, L.; Li, C.; Zhao, W. Diagnostic role of gallium-68 DOTATOC and gallium-68 DOTATATE PET in patients with neuroendocrine tumors: A meta-analysis. Acta Radiol. 2014, 55, 389-398. [CrossRef] [PubMed]

33. Deppen, S.A.; Blume, J.; Bobbey, A.J.; Shah, C.; Graham, M.M.; Lee, P.; Delbeke, D.; Walker, R.C. 68Ga-DOTATATE compared with 111In-DTPA-octreotide and conventional imaging for pulmonary and gastroenteropancreatic neuroendocrine tumors: A systematic review and meta-analysis. J. Nucl. Med. 2016, 57, 872-878. [CrossRef] [PubMed]

34. Bauckneht, M.; Albano, D.; Annunziata, S.; Santo, G.; Guglielmo, P.; Frantellizzi, V.; Branca, A.; Ferrari, C.; Vento, A.; Mirabile, A.; et al. Somatostatin receptor PET/CT imaging for the detection and staging of pancreatic NET: A systematic review and meta-analysis. Diagnostics 2020, 10, 598. [CrossRef] [PubMed]

35. Piccardo, A.; Fiz, F.; Bottoni, G.; Ugolini, M.; Noordzij, W.; Trimboli, P. Head-to-Head comparison between 18 F-DOPA PET/CT and 68 Ga-DOTA peptides PET/CT in detecting intestinal neuroendocrine tumours: A systematic review and meta-analysis. Clin. Endocrinol. 2021, 95, 595-605. [CrossRef] [PubMed]

36. Jiang, Y.; Hou, G.; Cheng, W. The utility of 18F-FDG and 68Ga-DOTA-Peptide PET/CT in the evaluation of primary pulmonary carcinoid: A systematic review and meta-analysis. Medicine 2019, 98, e14769. [CrossRef]

37. Liu, X.; Li, N.; Jiang, T.; Xu, H.; Ran, Q.; Shu, Z.; Wu, J.; Li, Y.; Zhou, S.; Zhang, B. Comparison of gallium-68 somatostatin receptor and 18F-fluorodeoxyglucose positron emission tomography in the diagnosis of neuroendocrine tumours: A systematic review and meta-analysis. Hell J. Nucl. Med. 2020, 23, 188-200. [CrossRef]

38. Ma, H.; Kan, Y.; Yang, J.-G. Clinical value of 68Ga-DOTA-SSTR PET/CT in the diagnosis and detection of neuroendocrine tumors of unknown primary origin: A systematic review and meta-analysis. Acta Radiol. 2021, 62, 1217-1228. [CrossRef] [PubMed]

39. Dosso, S.D.; Treglia, G.; Pascale, M.; Tamburello, A.; Santhanam, P.; Kroiss, A.S.; Mestre, R.P.; Saletti, P.; Giovanella, L. Detection rate of unknown primary tumour by using somatostatin receptor PET/CT in patients with metastatic neuroendocrine tumours: A meta-analysis. Endocrine 2019, 64, 456-468. [CrossRef] [PubMed] 
40. Kan, Y.; Zhang, S.; Wang, W.; Liu, J.; Yang, J.; Wang, Z. 68Ga-somatostatin receptor analogs and 18F-FDG PET/CT in the localization of metastatic pheochromocytomas and paragangliomas with germline mutations: A meta-analysis. Acta Radiol. 2018, 59, 1466-1474. [CrossRef]

41. Han, S.; Suh, C.H.; Woo, S.; Kim, Y.J.; Lee, J.J. Performance of 68Ga-DOTA-conjugated somatostatin receptor-targeting peptide PET in detection of pheochromocytoma and paraganglioma: A systematic review and metaanalysis. J. Nucl. Med. 2019, 60, 369-376. [CrossRef]

42. Treglia, G.; Tamburello, A.; Giovanella, L. Detection rate of somatostatin receptor PET in patients with recurrent medullary thyroid carcinoma: A systematic review and a meta-analysis. Hormones 2017, 16, 362-372. [CrossRef]

43. Ambrosini, V.; Campana, D.; Polverari, G.; Peterle, C.; Diodato, S.; Ricci, C.; Allegri, V.; Casadei, R.; Tomassetti, P.; Fanti, S. Prognostic value of 68Ga-DOTANOC PET/CT SUVmax in patients with neuroendocrine tumors of the pancreas. J. Nucl. Med. 2015, 56, 1843-1848. [CrossRef]

44. Velikyan, I.; Sundin, A.; Sorensen, J.; Lubberink, M.; Sandstrom, M.; Garske-Roman, U.; Lundqvist, H.; Granberg, D.; Eriksson, B. Quantitative and qualitative intrapatient comparison of 68Ga-DOTATOC and 68Ga-DOTATATE: Net uptake rate for accurate quantification. J. Nucl. Med. 2014, 55, 204-210. [CrossRef] [PubMed]

45. Oksuz, M.O.; Winter, L.; Pfannenberg, C.; Reischl, G.; Mussig, K.; Bares, R.; Dittmann, H. Peptide receptor radionuclide therapy of neuroendocrine tumors with (90)Y-DOTATOC: Is treatment response predictable by pre-therapeutic uptake of (68)Ga-DOTATOC? Diagn. Interv. Imaging 2014, 95, 289-300. [CrossRef]

46. Kratochwil, C.; Stefanova, M.; Mavriopoulou, E.; Holland-Letz, T.; Dimitrakopoulou-Strauss, A.; Afshar-Oromieh, A.; Mier, W.; Haberkorn, U.; Giesel, F.L. SUV of [68Ga]DOTATOC-PET/CT predicts response probability of PRRT in neuroendocrine tumors. Mol. Imaging Biol. 2015, 17, 313-318. [CrossRef] [PubMed]

47. Toriihara, A.; Baratto, L.; Nobashi, T.; Park, S.; Hatami, N.; Davidzon, G.; Kunz, P.L.; Iagaru, A. Prognostic value of somatostatin receptor expressing tumor volume calculated from 68Ga-DOTATATE PET/CT in patients with well-differentiated neuroendocrine tumors. Eur. J. Nucl. Med. Mol. Imaging 2019, 46, 2244-2251. [CrossRef]

48. Krenning, E.P.; Valkema, R.; Kooij, P.P.; Breeman, W.A.; Bakker, W.H.; de Herder, W.W.; vanEijck, C.H.; Kwekkeboom, D.J.; de Jong, M.; Pauwels, S. Scintigraphy and radionuclide therapy with [indium-111-labelled-diethyl triamine penta-acetic acid-DPhe1]-octreotide. Ital. J. Gastroenterol. Hepatol. 1999, 31 (Suppl. 2), S219-S223. [PubMed]

49. Hope, T.A.; Calais, J.; Zhang, L.; Dieckmann, W.; Millo, C. 111In-pentetreotide scintigraphy versus 68Ga-DOTATATE PET: Impact on krenning scores and effect of tumor burden. J. Nucl. Med. 2019, 60, 1266-1269. [CrossRef]

50. Subramaniam, R.M.; Bradshaw, M.L.; Lewis, K.; Pinho, D.; Shah, C.; Walker, R.C. ACR practice parameter for the performance of gallium-68 DOTATATE PET/CT for neuroendocrine tumors. Clin. Nucl. Med. 2018, 43, 899-908. [CrossRef] [PubMed]

51. Werner, R.A.; Solnes, L.B.; Javadi, M.S.; Weich, A.; Gorin, M.A.; Pienta, K.J.; Higuchi, T.; Buck, A.K.; Pomper, M.G.; Rowe, S.P.; et al. SSTR-RADS version 1.0 as a reporting system for SSTR PET imaging and selection of potential PRRT candidates: A proposed standardization framework. J. Nucl. Med. 2018, 59, 1085-1091. [CrossRef]

52. Werner, R.A.; Bundschuh, R.A.; Bundschuh, L.; Javadi, M.S.; Higuchi, T.; Weich, A.; Sheikhbahaei, S.; Pienta, K.J.; Buck, A.K.; Pomper, M.G.; et al. Molecular imaging reporting and data systems (MI-RADS): A generalizable framework for targeted radiotracers with theranostic implications. Ann. Nucl. Med. 2018, 32, 512-522. [CrossRef]

53. Werner, R.A.; Thackeray, J.T.; Pomper, M.G.; Bengel, F.M.; Gorin, M.A.; Derlin, T.; Rowe, S.P. Recent updates on molecular imaging reporting and data systems (MI-RADS) for theranostic radiotracers-navigating pitfalls of SSTR-and PSMA-targeted PET/CT. J. Clin. Med. 2019, 8, E1060. [CrossRef] [PubMed]

54. Hicks, R.J.; Dromain, C.; Herder, W.W.d.; Costa, F.P.; Deroose, C.M.; Frilling, A.; Koumarianou, A.; Krenning, E.P.; Raymond, E.; Bodei, L.; et al. ENETS standardized (synoptic) reporting for molecular imaging studies in neuroendocrine tumours. J. Neuroendocr. 2021, e13040. [CrossRef] [PubMed]

55. Castano, J.P.; Sundin, A.; Maecke, H.R.; Villabona, C.; Vazquez-Albertino, R.; Navarro, E.; Oberg, K. Gastrointestinal neuroendocrine tumors (NETs): New diagnostic and therapeutic challenges. Cancer Metastasis Rev. 2014, 33, 353-359. [CrossRef] [PubMed]

56. Campana, D.; Ambrosini, V.; Pezzilli, R.; Fanti, S.; Labate, A.M.M.; Santini, D.; Ceccarelli, C.; Nori, F.; Franchi, R.; Corinaldesi, R.; et al. Standardized uptake values of (68)Ga-DOTANOC PET: A promising prognostic tool in neuroendocrine tumors. J. Nucl. Med. 2010, 51, 353-359. [CrossRef] [PubMed]

57. Lee, D.Y.; Kim, Y.-I. Prognostic value of maximum standardized uptake value in 68Ga-somatostatin receptor positron emission tomography for neuroendocrine tumors: A systematic review and meta-analysis. Clin. Nucl. Med. 2019, 44, 777-783. [CrossRef]

58. Dong, D.-H.; Zhang, X.-F.; Lopez-Aguiar, A.G.; Poultsides, G.; Makris, E.; Rocha, F.; Kanji, Z.; Weber, S.; Fisher, A.; Fields, R.; et al. Tumor burden score predicts tumor recurrence of non-functional pancreatic neuroendocrine tumors after curative resection. $H P B$ 2020, 22, 1149-1157. [CrossRef]

59. Lv, Y.; Han, X.; Xu, X.-F.; Ji, Y.; Zhou, Y.-H.; Sun, H.-C.; Zhou, J.; Fan, J.; Lou, W.-H.; Huang, C. Risk factors affecting prognosis in metachronous liver metastases from WHO classification G1 and G2 gastroenteropancreatic neuroendocrine tumors after initial R0 surgical resection. BMC Cancer 2019, 19, 335. [CrossRef] [PubMed]

60. Graf, J.; Pape, U.-F.; Jann, H.; Denecke, T.; Arsenic, R.; Brenner, W.; Pavel, M.; Prasad, V. Prognostic significance of somatostatin receptor heterogeneity in progressive neuroendocrine tumor treated with Lu-177 DOTATOC or Lu-177 DOTATATE. Eur. J. Nucl. Med. Mol. Imaging 2020, 47, 881-894. [CrossRef] 
61. Binderup, T.; Knigge, U.; Loft, A.; Federspiel, B.; Kjaer, A. 18F-fluorodeoxyglucose positron emission tomography predicts survival of patients with neuroendocrine tumors. Clin. Cancer Res. 2010, 16, 978-985. [CrossRef]

62. Ezziddin, S.; Attassi, M.; Yong-Hing, C.J.; Ahmadzadehfar, H.; Willinek, W.; Grunwald, F.; Guhlke, S.; Biersack, H.-J.; Sabet, A. Predictors of long-term outcome in patients with well-differentiated gastroenteropancreatic neuroendocrine tumors after peptide receptor radionuclide therapy with 177Lu-octreotate. J. Nucl. Med. 2014, 55, 183-190. [CrossRef]

63. Sansovini, M.; Severi, S.; Ianniello, A.; Nicolini, S.; Fantini, L.; Mezzenga, E.; Ferroni, F.; Scarpi, E.; Monti, M.; Bongiovanni, A.; et al. Long-term follow-up and role of FDG PET in advanced pancreatic neuroendocrine patients treated with 177Lu-D OTATATE. Eur. J. Nucl. Med. Mol. Imaging 2017, 44, 490-499. [CrossRef] [PubMed]

64. Nilica, B.; Waitz, D.; Stevanovic, V.; Uprimny, C.; Kendler, D.; Buxbaum, S.; Warwitz, B.; Gerardo, L.; Henninger, B.; Virgolini, I.; et al. Direct comparison of 68Ga-DOTA-TOC and 18F-FDG PET/CT in the follow-up of patients with neuroendocrine tumour treated with the first full peptide receptor radionuclide therapy cycle. Eur. J. Nucl. Med. Mol. Imaging 2016, 43, 1585-1592. [CrossRef] [PubMed]

65. Hofman, M.S.; Michael, M.; Kashyap, R.; Hicks, R.J. Modifying the poor prognosis associated with 18F-FDG-avid NET with peptide receptor chemo-radionuclide therapy (PRCRT). J. Nucl. Med. 2015, 56, 968-969. [CrossRef] [PubMed]

66. Lu, Y.-Y.; Chen, J.-H.; Liang, J.-A.; Chu, S.; Lin, W.-Y.; Kao, C.-H. 18F-FDG PET or PET/CT for detecting extensive disease in small-cell lung cancer: A systematic review and meta-analysis. Nucl. Med. Commun. 2014, 35, 697-703. [CrossRef] [PubMed]

67. Treglia, G.; Kakhki, V.R.D.; Giovanella, L.; Sadeghi, R. Diagnostic performance of fluorine-18-fluorodeoxyglucose positron emission tomography in patients with merkel cell carcinoma: A systematic review and meta-analysis. Am. J. Clin. Dermatol. 2013, 14, 437-447. [CrossRef]

68. Alevroudis, E.; Spei, M.-E.; Chatziioannou, S.N.; Tsoli, M.; Wallin, G.; Kaltsas, G.; Daskalakis, K. Clinical utility of 18F-FDG PET in neuroendocrine tumors prior to peptide receptor radionuclide therapy: A systematic review and meta-analysis. Cancers 2021, 13, 1813. [CrossRef] [PubMed]

69. Han, S.; Lee, H.S.; Woo, S.; Kim, T.-H.; Yoo, C.; Ryoo, B.-Y.; Ryu, J.-S. Prognostic value of 18F-FDG PET in neuroendocrine neoplasm: A systematic review and meta-analysis. Clin. Nucl. Med. 2021, ahead of print. [CrossRef]

70. Christensen, T.N.; Andersen, P.K.; Langer, S.W.; Fischer, B.M.B. Prognostic value of 18F-FDG-PET Parameters in patients with small cell lung cancer: A meta-analysis and review of current literature. Diagnostics 2021, 11, 174. [CrossRef]

71. Chan, D.L.; Pavlakis, N.; Schembri, G.P.; Bernard, E.J.; Hsiao, E.; Hayes, A.; Barnes, T.; Diakos, C.; Khasraw, M.; Samra, J.; et al. Dual somatostatin receptor/FDG PET/CT imaging in metastatic neuroendocrine tumours: Proposal for a novel grading scheme with prognostic significance. Theranostics 2017, 7, 1149-1158. [CrossRef]

72. Chan, D.L.; Ulaner, G.A.; Pattison, D.; Wyld, D.; Ladwa, R.; Kirchner, J.; Li, B.T.; Lai, W.V.; Pavlakis, N.; Roach, P.J.; et al. Dual PET imaging in bronchial neuroendocrine neoplasms: The NETPET score as a prognostic biomarker. J. Nucl. Med. 2021, 62, 1278-1284. [CrossRef]

73. Kayani, I.; Bomanji, J.B.; Groves, A.; Conway, G.; Gacinovic, S.; Win, T.; Dickson, J.; Caplin, M.; Ell, P.J. Functional imaging of neuroendocrine tumors with combined PET/CT using 68Ga-DOTATATE (DOTA-DPhe1,tyr3-octreotate) and 18F-FDG. Cancer 2008, 112, 2447-2455. [CrossRef] [PubMed]

74. Pavel, M.; Oberg, K.; Falconi, M.; Krenning, E.P.; Sundin, A.; Perren, A.; Berruti, A. Gastroenteropancreatic neuroendocrine neoplasms: ESMO clinical practice guidelines for diagnosis, treatment and follow-up. Ann. Oncol. 2020, 31, 844-860. [CrossRef] [PubMed]

75. Beyer, L.; Gosewisch, A.; Lindner, S.; Volter, F.; Mittlmeier, L.M.; Tiling, R.; Brendel, M.; Cyran, C.C.; Unterrainer, M.; Rubenthaler, J.; et al. Dosimetry and optimal scan time of [18F]SiTATE-PET/CT in Patients with neuroendocrine tumours. Eur. J. Nucl. Med. Mol. Imaging 2021, 48, 3571-3581. [CrossRef] [PubMed]

76. Pauwels, E.; Cleeren, F.; Tshibangu, T.; Koole, M.; Serdons, K.; Dekervel, J.; Cutsem, E.V.; Verslype, C.; Laere, K.V.; Bormans, G.; et al. [18F]AlF-NOTA-octreotide PET imaging: Biodistribution, dosimetry and first comparison with [68Ga]Ga-DOTATATE in neuroendocrine tumour patients. Eur. J. Nucl. Med. Mol. Imaging 2020, 47, 3033-3046. [CrossRef] [PubMed]

77. Ilhan, H.; Lindner, S.; Todica, A.; Cyran, C.C.; Tiling, R.; Auernhammer, C.J.; Spitzweg, C.; Boeck, S.; Unterrainer, M.; Gildehaus, F.J.; et al. Biodistribution and first clinical results of 18F-SiFAlin-TATE PET: A novel 18F-labeled somatostatin analog for imaging of neuroendocrine tumors. Eur. J. Nucl. Med. Mol. Imaging 2020, 47, 870-880. [CrossRef]

78. Hou, J.; Long, T.; Yang, N.; Chen, D.; Zeng, S.; Zheng, K.; Liao, G.; Hu, S. Biodistribution of 18F-AlF-NOTA-octreotide in different organs and characterization of uptake in neuroendocrine neoplasms. Mol. Imaging Biol. 2021, 23, 827-835. [CrossRef] [PubMed]

79. Hicks, R.J.; Jackson, P.; Kong, G.; Ware, R.E.; Hofman, M.S.; Pattison, D.A.; Akhurst, T.A.; Drummond, E.; Roselt, P.; Callahan, J.; et al. 64Cu-SARTATE PET imaging of patients with neuroendocrine tumors demonstrates high tumor uptake and retention, potentially allowing prospective dosimetry for peptide receptor radionuclide therapy. J. Nucl. Med. 2019, 60, 777-785. [CrossRef]

80. Shur, J.D.; Doran, S.J.; Kumar, S.; Dafydd, D.A.; Downey, K.; O'Connor, J.P.B.; Papanikolaou, N.; Messiou, C.; Koh, D.-M.; Orton, M.R. Radiomics in oncology: A practical guide. Radiographics 2021, 41, 1717-1732. [CrossRef]

81. Partouche, E.; Yeh, R.; Eche, T.; Rozenblum, L.; Carrere, N.; Guimbaud, R.; Dierickx, L.O.; Rousseau, H.; Dercle, L.; Mokrane, F.-Z. Updated trends in imaging practices for pancreatic neuroendocrine tumors (PNETs): A systematic review and meta-analysis to pave the way for standardization in the new era of big data and artificial intelligence. Front. Oncol. 2021, 11, 628408. [CrossRef]

82. Atkinson, C.; Ganeshan, B.; Endozo, R.; Wan, S.; Aldridge, M.D.; Groves, A.M.; Bomanji, J.B.; Gaze, M.N. Radiomics-Based Texture Analysis of 68Ga-DOTATATE Positron Emission Tomography and Computed Tomography Images as a Prognostic Biomarker in Adults With Neuroendocrine Cancers Treated With 177Lu-DOTATATE. Front. Oncol. 2021, 11, 686235. [CrossRef] 
83. Thuillier, P.; Liberini, V.; Rampado, O.; Gallio, E.; Santi, B.D.; Ceci, F.; Metovic, J.; Papotti, M.; Volante, M.; Molinari, F.; et al. Diagnostic value of conventional PET parameters and radiomic features extracted from 18F-FDG-PET/CT for histologic subtype classification and characterization of lung neuroendocrine neoplasms. Biomedicines 2021, 9, 281. [CrossRef] [PubMed]

84. Liberini, V.; De Santi, B.; Rampado, O.; Gallio, E.; Dionisi, B.; Ceci, F.; Polverari, G.; Thuillier, P.; Molinari, F.; Deandreis, D. Impact of segmentation and discretization on radiomic features in 68Ga-DOTA-TOC PET/CT images of neuroendocrine tumor. EJNMMI Phys. 2021, 8, 21. [CrossRef]

85. Liberini, V.; Rampado, O.; Gallio, E.; De Santi, B.; Ceci, F.; Dionisi, B.; Thuillier, P.; Ciuffreda, L.; Piovesan, A.; Fioroni, F.; et al. 68Ga-DOTATOC PET/CT-based radiomic analysis and PRRT outcome: A preliminary evaluation based on an exploratory radiomic analysis on two patients. Front. Med. 2020, 7, 601853. [CrossRef] [PubMed]

86. Weber, M.; Kessler, L.; Schaarschmidt, B.; Fendler, W.P.; Lahner, H.; Antoch, G.; Umutlu, L.; Herrmann, K.; Rischpler, C. Treatment-related changes in neuroendocrine tumors as assessed by textural features derived from 68Ga-DOTATOC PET/MRI with simultaneous acquisition of apparent diffusion coefficient. BMC Cancer 2020, 20, 326. [CrossRef] [PubMed]

87. Bevilacqua, A.; Calabro, D.; Malavasi, S.; Ricci, C.; Casadei, R.; Campana, D.; Baiocco, S.; Fanti, S.; Ambrosini, V. A [68Ga]GaDOTANOC PET/CT radiomic model for non-invasive prediction of tumour grade in pancreatic neuroendocrine tumours. Diagnostics 2021, 11, 870. [CrossRef] [PubMed]

88. Mapelli, P.; Partelli, S.; Salgarello, M.; Doraku, J.; Pasetto, S.; Rancoita, P.M.V.; Muffatti, F.; Bettinardi, V.; Presotto, L.; Andreasi, V.; et al. Dual tracer 68Ga-DOTATOC and 18F-FDG PET/Computed tomography radiomics in pancreatic neuroendocrine neoplasms: An endearing tool for preoperative risk assessment. Nucl. Med. Commun. 2020, 41, 896-905. [CrossRef]

89. Fani, M.; Nicolas, G.P.; Wild, D. Somatostatin receptor antagonists for imaging and therapy. J. Nucl. Med. 2017, 58, 61S-66S. [CrossRef]

90. Nicolas, G.P.; Schreiter, N.; Kaul, F.; Uiters, J.; Bouterfa, H.; Kaufmann, J.; Erlanger, T.E.; Cathomas, R.; Christ, E.; Fani, M.; et al. Sensitivity comparison of $68 \mathrm{Ga}$-OPS202 and 68Ga-DOTATOC PET/CT in patients with gastroenteropancreatic neuroendocrine tumors: A prospective phase II imaging study. J. Nucl. Med. 2018, 59, 915-921. [CrossRef] [PubMed]

91. Krebs, S.; Pandit-Taskar, N.; Reidy, D.; Beattie, B.J.; Lyashchenko, S.K.; Lewis, J.S.; Bodei, L.; Weber, W.A.; O’Donoghue, J.A. Biodistribution and radiation dose estimates for 68Ga-DOTA-JR11 in patients with metastatic neuroendocrine tumors. Eur. J. Nucl. Med. Mol. Imaging 2019, 46, 677-685. [CrossRef]

92. Zhu, W.; Cheng, Y.; Wang, X.; Yao, S.; Bai, C.; Zhao, H.; Jia, R.; Xu, J.; Huo, L. Head-to-head comparison of 68Ga-DOTA-JR11 and 68Ga-DOTATATE PET/CT in patients with metastatic, well-differentiated neuroendocrine tumors: A prospective study. J. Nucl. Med. 2020, 61, 897-903. [CrossRef]

93. Wild, D.; Fani, M.; Fischer, R.; Pozzo, L.D.; Kaul, F.; Krebs, S.; Fischer, R.; Rivier, J.E.F.; Reubi, J.C.; Maecke, H.R.; et al. Comparison of somatostatin receptor agonist and antagonist for peptide receptor radionuclide therapy: A pilot study. J. Nucl. Med. 2014, 55, 1248-1252. [CrossRef] [PubMed]

94. Krebs, S.; O’Donoghue, J.A.; Biegel, E.; Beattie, B.J.; Reidy, D.; Lyashchenko, S.K.; Lewis, J.S.; Bodei, L.; Weber, W.A.; Pandit-Taskar, N. Comparison of 68Ga-DOTA-JR11 PET/CT with dosimetric 177Lu-satoreotide tetraxetan (177Lu-DOTA-JR11) SPECT/CT in patients with metastatic neuroendocrin.ne tumors undergoing peptide receptor radionuclide therapy. Eur. J. Nucl. Med. Mol. Imaging 2020, 47, 3047-3057. [CrossRef] [PubMed]

95. Zhu, W.; Cheng, Y.; Jia, R.; Zhao, H.; Bai, C.; Xu, J.; Yao, S.; Huo, L. A prospective, randomized, double-blind study to evaluate the safety, biodistribution, and dosimetry of 68ga-nodaga- $\operatorname{lm} 3$ and 68 ga-dota- $\operatorname{lm} 3$ in patients with well-differentiated neuroendocrine tumors. J. Nucl. Med. 2021, 62, 1398-1405. [CrossRef] [PubMed]

96. Baum, R.P.; Zhang, J.; Schuchardt, C.; Muller, D.; Macke, H. First-in-humans study of the SSTR antagonist 177Lu-DOTA-LM3 for peptide receptor radionuclide therapy in patients with metastatic neuroendocrine neoplasms: Dosimetry, safety, and efficacy. $J$. Nucl. Med. 2021, 62, 1571-1581. [CrossRef] [PubMed]

97. Turner, J.H. An introduction to the clinical practice of theranostics in oncology. Br. J. Radiol. 2018, 91, 20180440. [CrossRef]

98. Bodei, L.; Mueller-Brand, J.; Baum, R.P.; Pavel, M.E.; Horsch, D.; O’Dorisio, M.S.; O’Dorisio, T.M.; O’Dorisiol, T.M.; Howe, J.R.; Cremonesi, M.; et al. The joint IAEA, EANM, and SNMMI practical guidance on peptide receptor radionuclide therapy (PRRNT) in neuroendocrine tumours. Eur. J. Nucl. Med. Mol. Imaging 2013, 40, 800-816. [CrossRef] [PubMed]

99. Oberg, K.E.; Reubi, J.-C.; Kwekkeboom, D.J.; Krenning, E.P. Role of somatostatins in gastroenteropancreatic neuroendocrine tumor development and therapy. Gastroenterology 2010, 139, 742-753.e1. [CrossRef]

100. Eychenne, R.; Bouvry, C.; Bourgeois, M.; Loyer, P.; Benoist, E.; Lepareur, N. Overview of radiolabeled somatostatin analogs for cancer imaging and therapy. Molecules 2020, 25, E4012. [CrossRef]

101. Dash, A.; Chakraborty, S.; Pillai, M.R.A.; Knapp, F.F.R. Peptide receptor radionuclide therapy: An overview. Cancer Biother. Radiopharm. 2015, 30, 47-71. [CrossRef]

102. Lu, X.; Lu, C.; Yang, Y.; Shi, X.; Wang, H.; Yang, N.; Yang, K.; Zhang, X. Current status and trends in peptide receptor radionuclide therapy in the past 20 years (2000-2019): A bibliometric study. Front. Pharm. 2021, 12, 624534. [CrossRef]

103. Krenning, E.P.; Bakker, W.H.; Breeman, W.A.; Koper, J.W.; Kooij, P.P.; Ausema, L.; Lameris, J.S.; Reubi, J.C.; Lamberts, S.W. Localisation of endocrine-related tumours with radioiodinated analogue of somatostatin. Lancet 1989, 1, 242-244. [CrossRef]

104. Anthony, L.B.; Woltering, E.A.; Espenan, G.D.; Cronin, M.D.; Maloney, T.J.; McCarthy, K.E. Indium-111-pentetreotide prolongs survival in gastroenteropancreatic malignancies. Semin. Nucl. Med. 2002, 32, 123-132. [CrossRef] [PubMed] 
105. Kwekkeboom, D.J.; Kam, B.L.; van Essen, M.; Teunissen, J.J.M.; van Eijck, C.H.J.; Valkema, R.; Jong, M.D.; Herder, W.W.D.; Krenning, E.P. Somatostatin-receptor-based imaging and therapy of gastroenteropancreatic neuroendocrine tumors. Endocr. Relat. Cancer 2010, 17, R53-R73. [CrossRef]

106. Krenning, E.P.; Kooij, P.P.; Bakker, W.H.; Breeman, W.A.; Postema, P.T.; Kwekkeboom, D.J.; Oei, H.Y.; Jong, M.d.; Visser, T.J.; Reijs, A.E. Radiotherapy with a radiolabeled somatostatin analogue, [111In-DTPA-D-Phe1]-octreotide. A case history. N. Y. Acad. Sci. Ann. 1994, 733, 496-506. [CrossRef] [PubMed]

107. Otte, A.; Jermann, E.; Behe, M.; Goetze, M.; Bucher, H.C.; Roser, H.W.; Heppeler, A.; Mueller-Brand, J.; Maecke, H.R. DOTATOC: A powerful new tool for receptor-mediated radionuclide therapy. Eur. J. Nucl. Med. 1997, 24, 792-795. [CrossRef] [PubMed]

108. Albert, R.; Smith-Jones, P.; Stolz, B.; Simeon, C.; Knecht, H.; Bruns, C.; Pless, J. Direct synthesis of [DOTA-DPhe1]-octreotide and [DOTA-DPhe1,Tyr3]-octreotide (SMT487): Two conjugates for systemic delivery of radiotherapeutical nuclides to somatostatin receptor positive tumors in man. Bioorg. Med. Chem. Lett. 1998, 8, 1207-1210. [CrossRef]

109. Kwekkeboom, D.J.; Teunissen, J.J.; Bakker, W.H.; Kooij, P.P.; de Herder, W.W.; Feelders, R.A.; van Eijck, C.H.; Esser, J.-P.; Kam, B.L.; Krenning, E.P. Radiolabeled somatostatin analog [177Lu-DOTA0,Tyr3] octreotate in patients with endocrine gastroenteropancreatic tumors. J. Clin. Oncol. 2005, 23, 2754-2762. [CrossRef]

110. Sabet, A.; Haslerud, T.; Pape, U.-F.; Sabet, A.; Ahmadzadehfar, H.; Grunwald, F.; Guhlke, S.; Biersack, H.-J.; Ezziddin, S. Outcome and toxicity of salvage therapy with $177 \mathrm{Lu}$-octreotate in patients with metastatic gastroenteropancreatic neuroendocrine tumours. Eur. J. Nucl. Med. Mol. Imaging 2014, 41, 205-210. [CrossRef]

111. Kwekkeboom, D.J.; Krenning, E.P. Peptide receptor radionuclide therapy in the treatment of neuroendocrine tumors. Hematol. Clin. N. Am. 2016, 30, 179-191. [CrossRef]

112. Vinjamuri, S.; Gilbert, T.M.; Banks, M.; McKane, G.; Maltby, P.; Poston, G.; Weissman, H.; Palmer, D.H.; Vora, J.; Pritchard, D.M.; et al. Peptide receptor radionuclide therapy with (90)Y-DOTATATE/(90)Y-DOTATOC in patients with progressive metastatic neuroendocrine tumours: Assessment of response, survival and toxicity. Br. J. Cancer 2013, 108, 1440-1448. [CrossRef] [PubMed]

113. Valkema, R.; Pauwels, S.; Kvols, L.K.; Barone, R.; Jamar, F.; Bakker, W.H.; Kwekkeboom, D.J.; Bouterfa, H.; Krenning, E.P. Survival and response after peptide receptor radionuclide therapy with [90Y-DOTA0,Tyr3]octreotide in patients with advanced gastroenteropancreatic neuroendocrine tumors. Semin. Nucl. Med. 2006, 36, 147-156. [CrossRef]

114. Filice, A.; Fraternali, A.; Frasoldati, A.; Asti, M.; Grassi, E.; Massi, L.; Sollini, M.; Froio, A.; Erba, P.A.; Versari, A. Radiolabeled somatostatin analogues therapy in advanced neuroendocrine tumors: A single centre experience. J. Oncol. 2012, $2012,320198$. [CrossRef] [PubMed]

115. Mariniello, A.; Bodei, L.; Tinelli, C.; Baio, S.M.; Gilardi, L.; Colandrea, M.; Papi, S.; Valmadre, G.; Fazio, N.; Galetta, D.; et al. Long-term results of PRRT in advanced bronchopulmonary carcinoid. Eur. J. Nucl. Med. Mol. Imaging 2016, 43, 441-452. [CrossRef] [PubMed]

116. Bodei, L.; Cremonesi, M.; Grana, C.M.; Fazio, N.; Iodice, S.; Baio, S.M.; Bartolomei, M.; Lombardo, D.; Ferrari, M.E.; Sansovini, M.; et al. Peptide receptor radionuclide therapy with ${ }^{177}$ Lu-DOTATATE: The IEO phase I-II study. Eur. J. Nucl. Med. Mol. Imaging 2011, 38, 2125-2135. [CrossRef] [PubMed]

117. Kwekkeboom, D.J.; de Herder, W.W.; Kam, B.L.; van Eijck, C.H.; van Essen, M.; Kooij, P.P.; Feelders, R.A.; van Aken, M.O.; Krenning, E.P. Treatment with the radiolabeled somatostatin analog [177 Lu-DOTA 0,Tyr3]octreotate: Toxicity, efficacy, and survival. J. Clin. Oncol. 2008, 26, 2124-2130. [CrossRef]

118. Kunikowska, J.; Krolicki, L.; Hubalewska-Dydejczyk, A.; Mikołajczak, R.; Sowa-Staszczak, A.; Pawlak, D. Clinical results of radionuclide therapy of neuroendocrine tumours with 90Y-DOTATATE and tandem 90Y/177Lu-DOTATATE: Which is a better therapy option? Eur. J. Nucl. Med. Mol. Imaging 2011, 38, 1788-1797. [CrossRef]

119. Imhof, A.; Brunner, P.; Marincek, N.; Briel, M.; Schindler, C.; Rasch, H.; Macke, H.R.; Rochlitz, C.; Muller-Brand, J.; Walter, M.A. Response, survival, and long-term toxicity after therapy with the radiolabeled somatostatin analogue [90Y-DOTA]-TOC in metastasized neuroendocrine cancers. J. Clin. Oncol. 2011, 29, 2416-2423. [CrossRef]

120. Bodei, L.; Cremonesi, M.; Ferrari, M.; Pacifici, M.; Grana, C.M.; Bartolomei, M.; Baio, S.M.; Sansovini, M.; Paganelli, G. Long-term evaluation of renal toxicity after peptide receptor radionuclide therapy with 90Y-DOTATOC and 177Lu-DOTATATE: The role of associated risk factors. Eur. J. Nucl. Med. Mol. Imaging 2008, 35, 1847-1856. [CrossRef]

121. Bergsma, H.; van Lom, K.; Raaijmakers, M.H.G.P.; Konijnenberg, M.; Kam, B.L.B.L.R.; Teunissen, J.J.M.; de Herder, W.W.; Krenning, E.P.; Kwekkeboom, D.J. Persistent hematologic dysfunction after peptide receptor radionuclide therapy with 177LuDOTATATE: Incidence, course, and predicting factors in patients with gastroenteropancreatic neuroendocrine tumors. J. Nucl. Med. 2018, 59, 452-458. [CrossRef]

122. Bodei, L.; Kidd, M.; Paganelli, G.; Grana, C.M.; Drozdov, I.; Cremonesi, M.; Lepensky, C.; Kwekkeboom, D.J.; Baum, R.P.; Krenning, E.P.; et al. Long-term tolerability of PRRT in 807 patients with neuroendocrine tumours: The value and limitations of clinical factors. Eur. J. Nucl. Med. Mol. Imaging 2015, 42, 5-19. [CrossRef]

123. Rolleman, E.J.; Valkema, R.; de Jong, M.; Kooij, P.P.M.; Krenning, E.P. Safe and effective inhibition of renal uptake of radiolabelled octreotide by a combination of lysine and arginine. Eur. J. Nucl. Med. Mol. Imaging 2003, 30, 9-15. [CrossRef]

124. Bushnell, D.; Menda, Y.; O’Dorisio, T.; Madsen, M.; Miller, S.; Carlisle, T.; Squires, S.; Kahn, D.; Walkner, W.; Connolly, M.; et al. Effects of intravenous amino acid administration with Y-90 DOTA-Phe1-Tyr3-octreotide (SMT487[OctreoTher) treatment. Cancer Biother. Radiopharm. 2004, 19, 35-41. [CrossRef] [PubMed]

125. Van Der Zwan, W.A.; Bodei, L.; Mueller-Brand, J.; de Herder, W.W.; Kvols, L.K.; Kwekkeboom, D.J. GEPNETs update: Radionuclide therapy in neuroendocrine tumors. Eur. J. Endocrinol. 2015, 172, R1-R8. [CrossRef] [PubMed] 
126. Pauwels, S.; Barone, R.; Walrand, S.; Borson-Chazot, F.; Valkema, R.; Kvols, L.K.; Krenning, E.P.; Jamar, F. Practical dosimetry of peptide receptor radionuclide therapy with (90)Y-Labeled somatostatin analogs. J. Nucl. Med. 2005, 46 (Suppl. 1), 92S-98S. [PubMed]

127. Menda, Y.; Madsen, M.T.; O’Dorisio, T.M.; Sunderland, J.J.; Watkins, G.L.; Dillon, J.S.; Mott, S.L.; Schultz, M.K.; Zamba, G.K.D.; Bushnell, D.L.; et al. 90Y-DOTATOC dosimetry-based personalized peptide receptor radionuclide therapy. J. Nucl. Med. 2018, 59, 1692-1698. [CrossRef] [PubMed]

128. Hindorf, C.; Chittenden, S.; Causer, L.; Lewington, V.J.; Macke, H.R.; Flux, G.D. Dosimetry for (90)Y-DOTATOC therapies in patients with neuroendocrine tumors. Cancer Biother. Radiopharm. 2007, 22, 130-135. [CrossRef] [PubMed]

129. Sundlov, A.; Sjogreen-Gleisner, K.; Svensson, J.; Ljungberg, M.; Olsson, T.; Bernhardt, P.; Tennvall, J. Individualised 177LuDOTATATE treatment of neuroendocrine tumours based on kidney dosimetry. Eur. J. Nucl. Med. Mol. Imaging 2017, 44, 1480-1489. [CrossRef]

130. Hennrich, U.; Kopka, K. Lutathera ${ }^{\circledR}$ : The first FDA- and EMA-approved radiopharmaceutical for peptide receptor radionuclide therapy. Pharmaceuticals 2019, 12, E114. [CrossRef]

131. Strosberg, J.; El-Haddad, G.; Wolin, E.; Hendifar, A.; Yao, J.; Chasen, B.; Mittra, E.; Kunz, P.L.; Kulke, M.H.; Jacene, H.; et al. Phase 3 trial of 177Lu-dotatate for midgut neuroendocrine tumors. N. Engl. J. Med. 2017, 376, 125-135. [CrossRef]

132. Brabander, T.; Zwan, W.A.v.d.; Teunissen, J.J.M.; Kam, B.L.R.; Feelders, R.A.; Herder, W.W.d.; Eijck, C.H.J.v.; Franssen, G.J.H.; Krenning, E.P.; Kwekkeboom, D.J. Long-term efficacy, survival, and safety of [177Lu-DOTA0,Tyr3] octreotate in patients with gastroenteropancreatic and bronchial neuroendocrine tumors. Clin. Cancer Res. 2017, 23, 4617-4624. [CrossRef]

133. Singh, S.; Granberg, D.; Wolin, E.; Warner, R.; Sissons, M.; Kolarova, T.; Goldstein, G.; Pavel, M.; Oberg, K.; Leyden, J. Patientreported burden of a neuroendocrine tumor (NET) diagnosis: Results from the first global survey of patients with NETs. J. Glob. Oncol. 2017, 3, 43-53. [CrossRef] [PubMed]

134. Kulke, M.H.; Benson, A.B.; Bergsland, E.; Berlin, J.D.; Blaszkowsky, L.S.; Choti, M.A.; Clark, O.H.; Doherty, G.M.; Eason, J.; Emerson, L.; et al. Neuroendocrine tumors. J. Natl. Compr. Cancer Netw. 2012, 10, 724-764. [CrossRef] [PubMed]

135. Khan, S.; Krenning, E.P.; Essen, M.v.; Kam, B.L.; Teunissen, J.J.; Kwekkeboom, D.J. Quality of life in 265 patients with gastroenteropancreatic or bronchial neuroendocrine tumors treated with [177Lu-DOTA0,Tyr3]octreotate. J. Nucl. Med. 2011, 52, 1361-1368. [CrossRef] [PubMed]

136. Strosberg, J.; Wolin, E.; Chasen, B.; Kulke, M.; Bushnell, D.; Caplin, M.; Baum, R.P.; Kunz, P.; Hobday, T.; Hendifar, A.; et al. Health-related quality of life in patients with progressive midgut neuroendocrine tumors treated with 177Lu-dotatate in the phase III NETTER-1 trial. J. Clin. Oncol. 2018, 36, 2578-2584. [CrossRef] [PubMed]

137. Carlsen, E.A.; Fazio, N.; Granberg, D.; Grozinsky-Glasberg, S.; Ahmadzadehfar, H.; Grana, C.M.; Zandee, W.T.; Cwikla, J.; Walter, M.A.; Oturai, P.S.; et al. Peptide receptor radionuclide therapy in gastroenteropancreatic NEN G3: A multicenter cohort study. Endocr. Relat. Cancer 2019, 26, 227-239. [CrossRef]

138. Seregni, E.; Maccauro, M.; Chiesa, C.; Mariani, L.; Pascali, C.; Mazzaferro, V.; De Braud, F.; Buzzoni, R.; Milione, M.; Lorenzoni, A.; et al. Treatment with tandem [90Y]DOTA-TATE and [177Lu]DOTA-TATE of neuroendocrine tumours refractory to conventional therapy. Eur. J. Nucl. Med. Mol. Imaging 2014, 41, 223-230. [CrossRef] [PubMed]

139. Waldherr, C.; Pless, M.; Maecke, H.R.; Schumacher, T.; Crazzolara, A.; Nitzsche, E.U.; Haldemann, A.; Mueller-Brand, J. Tumor response and clinical benefit in neuroendocrine tumors after 7.4 GBq (90)Y-DOTATOC. J. Nucl. Med. 2002, 43, 610-616. [PubMed]

140. Hamiditabar, M.; Ali, M.; Roys, J.; Wolin, E.M.; O’Dorisio, T.M.; Ranganathan, D.; Tworowska, I.; Strosberg, J.R.; Delpassand, E.S. Peptide receptor radionuclide therapy with $177 \mathrm{Lu}$-octreotate in patients with somatostatin receptor expressing neuroendocrine tumors: Six years' assessment. Clin. Nucl. Med. 2017, 42, 436-443. [CrossRef]

141. Zandee, W.T.; Brabander, T.; Blazevic, A.; Minczeles, N.S.; Feelders, R.A.; de Herder, W.W.; Hofland, J. Peptide receptor radionuclide therapy with 177Lu-DOTATATE for symptomatic control of refractory carcinoid syndrome. J. Clin. Endocrinol. Metab. 2021, 106, e3665-e3672. [CrossRef]

142. Hope, T.A.; Bodei, L.; Chan, J.A.; El-Haddad, G.; Fidelman, N.; Kunz, P.L.; Mailman, J.; Menda, Y.; Metz, D.C.; Mittra, E.S.; et al. NANETS/SNMMI consensus statement on patient selection and appropriate use of 177Lu-DOTATATE peptide receptor radionuclide therapy. J. Nucl. Med. 2020, 61, 222-227. [CrossRef] [PubMed]

143. Al-Toubah, T.; Sikaria, D.; Jesurajan, J.; Bottiglieri, S.; Smith, J.; Pelle, E.; Hutchinson, T.; Strosberg, J.; El-Haddad, G. Comparison of nausea and vomiting associated with amino acid formulations coinfused with peptide receptor radionuclide therapy: Commercial parenteral nutrition formulas versus compounded arginine/lysine. Pancreas 2021, 50, 513-515. [CrossRef]

144. Apostolidis, L.; Dal Buono, A.; Merola, E.; Jann, H.; Jager, D.; Wiedenmann, B.; Winkler, E.C.; Pavel, M. Multicenter analysis of treatment outcomes for systemic therapy in well differentiated grade 3 neuroendocrine tumors (NET G3). Cancers 2021, 13, 1936. [CrossRef]

145. Merola, E.; Prasad, V.; Pascher, A.; Pape, U.-F.; Arsenic, R.; Denecke, T.; Fehrenbach, U.; Wiedenmann, B.; Pavel, M.E. Peritoneal carcinomatosis in gastro-entero-pancreatic neuroendocrine neoplasms: Clinical impact and effectiveness of the available therapeutic options. Neuroendocrinology 2020, 110, 517-524. [CrossRef] [PubMed]

146. Strosberg, J.R.; Al-Toubah, T.; Pelle, E.; Smith, J.; Haider, M.; Hutchinson, T.; Fleming, J.B.; El-Haddad, G. Risk of bowel obstruction in patients with mesenteric or peritoneal disease receiving peptide receptor radionuclide therapy. J. Nucl. Med. 2021, 62, 69-72. [CrossRef] [PubMed]

147. Nicolini, S.; Severi, S.; Ianniello, A.; Sansovini, M.; Ambrosetti, A.; Bongiovanni, A.; Scarpi, E.; Mauro, F.D.; Rossi, A.; Matteucci, F.; et al. Investigation of receptor radionuclide therapy with 177Lu-DOTATATE in patients with GEP-NEN and a high Ki-67 proliferation index. Eur. J. Nucl. Med. Mol. Imaging 2018, 45, 923-930. [CrossRef] 
148. Sharma, N.; Naraev, B.G.; Engelman, E.G.; Zimmerman, M.B.; Bushnell, D.L.; O’Dorisio, T.M.; O’Dorisio, M.S.; Menda, Y.; Muller-Brand, J.; Howe, J.R.; et al. Peptide receptor radionuclide therapy outcomes in a north american cohort with metastatic well-differentiated neuroendocrine tumors. Pancreas 2017, 46, 151-156. [CrossRef]

149. Aalbersberg, E.A.; Huizing, D.M.V.; Walraven, I.; de Wit-van der Veen, B.J.; Kulkarni, H.R.; Singh, A.; Stokkel, M.P.M.; Baum, R.P. Parameters to predict progression-free and overall survival after peptide receptor radionuclide therapy: A multivariate analysis in 782 patients. J. Nucl. Med. 2019, 60, 1259-1265. [CrossRef]

150. Baum, R.P.; Kulkarni, H.R.; Singh, A.; Kaemmerer, D.; Mueller, D.; Prasad, V.; Hommann, M.; Robiller, F.C.; Niepsch, K.; Franz, H.; et al. Results and adverse events of personalized peptide receptor radionuclide therapy with 90Yttrium and 177Lutetium in 1048 patients with neuroendocrine neoplasms. Oncotarget 2018, 9, 16932-16950. [CrossRef] [PubMed]

151. Emami, B.; Lyman, J.; Brown, A.; Coia, L.; Goitein, M.; Munzenrider, J.E.; Shank, B.; Solin, L.J.; Wesson, M. Tolerance of normal tissue to therapeutic irradiation. Int. J. Radiat. Oncol. Biol. Phys. 1991, 21, 109-122. [CrossRef]

152. Benua, R.S.; Cicale, N.R.; Sonenberg, M.; Rawson, R.W. The relation of radioiodine dosimetry to results and complications in the treatment of metastatic thyroid cancer. Am. J. Roentgenol. Radium Ther. Nucl. Med. 1962, 87, 171-182.

153. Sandstrom, M.; Garske-Roman, U.; Granberg, D.; Johansson, S.; Widström, C.; Eriksson, B.; Sundin, A.; Lundqvist, H.; Lubberink, M. Individualized dosimetry of kidney and bone marrow in patients undergoing 177Lu-DOTA-octreotate treatment. J. Nucl. Med. 2013, 54, 33-41. [CrossRef]

154. Haug, A.R. PRRT of neuroendocrine tumors: Individualized dosimetry or fixed dose scheme? EJNMMI Res. 2020, 10, 35. [CrossRef]

155. Strosberg, J.R.; Caplin, M.E.; Kunz, P.L.; Ruszniewski, P.B.; Bodei, L.; Hendifar, A.E.; Mittra, E.; Wolin, E.M.; Yao, J.C.; Pavel, M.E.; et al. Final overall survival in the phase 3 NETTER-1 study of lutetium-177-DOTATATE in patients with midgut neuroendocrine tumors. J. Clin. Oncol. 2021, 39, 4112. [CrossRef]

156. van der Zwan, W.A.; Brabander, T.; Kam, B.L.R.; Teunissen, J.J.M.; Feelders, R.A.; Hofland, J.; Krenning, E.P.; de Herder, W.W. Salvage peptide receptor radionuclide therapy with [177Lu-DOTA,Tyr3]octreotate in patients with bronchial and gastroenteropancreatic neuroendocrine tumours. Eur. J. Nucl. Med. Mol. Imaging 2019, 46, 704-717. [CrossRef] [PubMed]

157. Loser, A.; Schwarzenbock, S.M.; Heuschkel, M.; Willenberg, H.S.; Krause, B.J.; Kurth, J. Peptide receptor radionuclide therapy with 177Lu-DOTA-octreotate: Dosimetry, nephrotoxicity, and the effect of hematological toxicity on survival. Nucl. Med. Commun. 2018, 39, 236-246. [CrossRef]

158. Yordanova, A.; Mayer, K.; Brossart, P.; Gonzalez-Carmona, M.A.; Strassburg, C.P.; Essler, M.; Ahmadzadehfar, H. Safety of multiple repeated cycles of $177 \mathrm{Lu}$-octreotate in patients with recurrent neuroendocrine tumour. Eur. J. Nucl. Med. Mol. Imaging 2017, 44, 1207-1214. [CrossRef]

159. Garske-Roman, U.; Sandstrom, M.; Fross Baron, K.; Lundin, L.; Hellman, P.; Welin, S.; Johansson, S.; Khan, T.; Lundqvist, H.; Eriksson, B.; et al. Prospective observational study of 177Lu-DOTA-octreotate therapy in 200 patients with advanced metastasized neuroendocrine tumours (NETs): Feasibility and impact of a dosimetry-guided study protocol on outcome and toxicity. Eur. J. Nucl. Med. Mol. Imaging 2018, 45, 970-988. [CrossRef] [PubMed]

160. Ilan, E.; Sandstrom, M.; Wassberg, C.; Sundin, A.; Garske-Roman, U.; Eriksson, B.; Granberg, D.; Lubberink, M. Dose response of pancreatic neuroendocrine tumors treated with peptide receptor radionuclide therapy using 177Lu-DOTATATE. J. Nucl. Med. 2015, 56, 177-182. [CrossRef] [PubMed]

161. Jahn, U.; Ilan, E.; Sandstrom, M.; Garske-Roman, U.; Lubberink, M.; Sundin, A. 177Lu-DOTATATE peptide receptor radionuclide therapy: Dose response in small intestinal neuroendocrine tumors. Neuroendocrinology 2020, 110, 662-670. [CrossRef]

162. Sjogreen Gleisner, K.; Spezi, E.; Solny, P.; Gabina, P.M.; Cicone, F.; Stokke, C.; Chiesa, C.; Paphiti, M.; Brans, B.; Sandstrom, M.; et al. Variations in the practice of molecular radiotherapy and implementation of dosimetry: Results from a european survey. EJNMMI Phys. 2017, 4, 28. [CrossRef]

163. Strosberg, J.; Kunz, P.L.; Hendifar, A.; Yao, J.; Bushnell, D.; Kulke, M.H.; Baum, R.P.; Caplin, M.; Ruszniewski, P.; Delpassand, E.; et al. Impact of liver tumour burden, alkaline phosphatase elevation, and target lesion size on treatment outcomes with 177Lu-dotatate: An analysis of the NETTER-1 study. Eur. J. Nucl. Med. Mol. Imaging 2020, 47, 2372-2382. [CrossRef]

164. Das, S.; Dasari, A. Novel therapeutics for patients with well-differentiated gastroenteropancreatic neuroendocrine tumors. Ther. Adv. Med. Oncol. 2021, 13, 17588359211018048. [CrossRef] [PubMed]

165. Wahba, M.M.; Strosberg, J.; Avram, A.; Aparici, C.M. Abstract CT254: COMPETE phase III trial—Peptide receptor radionuclide therapy (PRRT) with 177Lu-edotreotide vs. everolimus in progressive GEP-NET. Cancer Res. 2021, 81, CT254. [CrossRef]

166. Pavel, M.E.; Rinke, A.; Baum, R.P. COMPETE trial: Peptide receptor radionuclide therapy (PRRT) with 177Lu-edotreotide vs. everolimus in progressive GEP-NET. Ann. Oncol. 2018, 29, viii478. [CrossRef]

167. Reidy-Lagunes, D.; Pandit-Taskar, N.; O’Donoghue, J.A.; Krebs, S.; Staton, K.D.; Lyashchenko, S.K.; Lewis, J.S.; Raj, N.; Gonen, M.; Lohrmann, C.; et al. phase I trial of well-differentiated neuroendocrine tumors (NETs) with radiolabeled somatostatin antagonist 177Lu-satoreotide tetraxetan. Clin. Cancer Res. 2019, 25, 6939-6947. [CrossRef]

168. Ballal, S.; Yadav, M.P.; Bal, C.; Sahoo, R.K.; Tripathi, M. Broadening horizons with 225Ac-DOTATATE targeted alpha therapy for gastroenteropancreatic neuroendocrine tumour patients stable or refractory to 177Lu-DOTATATE PRRT: First clinical experience on the efficacy and safety. Eur. J. Nucl. Med. Mol. Imaging 2020, 47, 934-946. [CrossRef] [PubMed]

169. Kratochwil, C.; Giesel, F.L.; Bruchertseifer, F.; Mier, W.; Apostolidis, C.; Boll, R.; Murphy, K.; Haberkorn, U.; Morgenstern, A. 213Bi-DOTATOC receptor-targeted alpha-radionuclide therapy induces remission in neuroendocrine tumours refractory to beta radiation: A first-in-human experience. Eur. J. Nucl. Med. Mol. Imaging 2014, 41, 2106-2119. [CrossRef] 
170. Delpassand, E.; Tworowska, I.; Esfandiari, R.; Torgue, J.; Hurt, J.D.; Nunez, R. Phase I dose-escalation study of alphamedix for targeted-alpha-emitter therapy of PRRT-naive neuroendocrine patients. JCO 2021, 39, 4117. [CrossRef]

171. Zhang, J.; Wang, H.; Jacobson, O.; Cheng, Y.; Niu, G.; Li, F.; Bai, C.; Zhu, Z.; Chen, X. Safety, pharmacokinetics, and dosimetry of a long-acting radiolabeled somatostatin analog 177Lu-DOTA-EB-TATE in patients with advanced metastatic neuroendocrine tumors. J. Nucl. Med. 2018, 59, 1699-1705. [CrossRef] [PubMed]

172. Telo, S.; Filice, A.; Versari, A.; Lamberti, G.; Campana, D.; Calabrò, D.; Fanti, S.; Ambrosini, V. Peptide receptor radionuclide therapy for GEP-NET: Consolidated knowledge and innovative applications. Clin. Transl. Imaging 2021, 9, 423-438. [CrossRef]

173. Claringbold, P.G.; Brayshaw, P.A.; Price, R.A.; Turner, J.H. Phase II study of radiopeptide 177Lu-octreotate and capecitabine therapy of progressive disseminated neuroendocrine tumours. Eur. J. Nucl. Med. Mol. Imaging 2011, 38, 302-311. [CrossRef]

174. Claringbold, P.G.; Price, R.A.; Turner, J.H. Phase I-II study of radiopeptide 177Lu-octreotate in combination with capecitabine and temozolomide in advanced low-grade neuroendocrine tumors. Cancer Biother. Radiopharm. 2012, 27, 561-569. [CrossRef] [PubMed]

175. Claringbold, P.G.; Turner, J.H. Pancreatic neuroendocrine tumor control: Durable objective response to combination 177Luoctreotate-capecitabine-temozolomide radiopeptide chemotherapy. Neuroendocrinology 2016, 103, 432-439. [CrossRef]

176. Campana, D.; Walter, T.; Pusceddu, S.; Gelsomino, F.; Graillot, E.; Prinzi, N.; Spallanzani, A.; Fiorentino, M.; Barritault, M.; Dall'Olio, F.; et al. Correlation between MGMT promoter methylation and response to temozolomide-based therapy in neuroendocrine neoplasms: An observational retrospective multicenter study. Endocrine 2018, 60, 490-498. [CrossRef] [PubMed]

177. Pavlakis, N.; Ransom, D.T.; Wyld, D.; Sjoquist, K.M.; Asher, R.; Gebski, V.; Wilson, K.; Kiberu, A.D.; Burge, M.E.; Macdonald, W.; et al. Australasian gastrointestinal trials group (AGITG) CONTROL NET study: Phase II study evaluating the activity of 177Lu-octreotate peptide receptor radionuclide therapy (LuTate PRRT) and capecitabine, temozolomide CAPTEM)—First results for pancreas and updated midgut neuroendocrine tumors (PNETS, MNETS). J. Clin. Oncol. 2020, 38, 4608. [CrossRef]

178. Kashyap, R.; Hofman, M.S.; Michael, M.; Kong, G.; Akhurst, T.; Eu, P.; Zannino, D.; Hicks, R.J. Favourable outcomes of (177)Luoctreotate peptide receptor chemoradionuclide therapy in patients with FDG-avid neuroendocrine tumours. Eur. J. Nucl. Med. Mol. Imaging 2015, 42, 176-185. [CrossRef] [PubMed]

179. Zhang, J.; Kulkarni, H.R.; Singh, A.; Niepsch, K.; Müller, D.; Baum, R.P. Peptide receptor radionuclide therapy in grade 3 neuroendocrine neoplasms: Safety and survival analysis in 69 patients. J. Nucl. Med. 2019, 60, 377-385. [CrossRef]

180. Thang, S.P.; Lung, M.S.; Kong, G.; Hofman, M.S.; Callahan, J.; Michael, M.; Hicks, R.J. Peptide receptor radionuclide therapy (PRRT) in european neuroendocrine tumour society (ENETS) grade 3 (G3) neuroendocrine neoplasia (NEN) - A single-institution retrospective analysis. Eur. J. Nucl. Med. Mol. Imaging 2018, 45, 262-277. [CrossRef]

181. Lamberti, G.; Andrini, E.; Sisi, M.; Federico, A.D.; Ricciuti, B. Targeting DNA damage response and repair genes to enhance anticancer immunotherapy: Rationale and clinical implication. Future Oncol. 2020, 16, 1751-1766. [CrossRef]

182. Purohit, N.K.; Shah, R.G.; Adant, S.; Hoepfner, M.; Shah, G.M.; Beauregard, J.-M. Potentiation of 177Lu-octreotate peptide receptor radionuclide therapy of human neuroendocrine tumor cells by PARP inhibitor. Oncotarget 2018, 9, 24693-24706. [CrossRef]

183. Chapman, T.R.; Kinsella, T.J. Ribonucleotide reductase inhibitors: A new look at an old target for radiosensitization. Front. Oncol. 2011, 1, 56. [CrossRef]

184. Chauhan, A.; Kunos, C.; Khouli, R.E.; Kolesar, J.; Weiss, H.L.; Carson, B.; Kidd, M.; Beumer, J.; Arnold, S.; Kohn, E.; et al. Abstract 674: A phase I trial of triapine and lutetium lu 177 dotatate in combination for well-differentiated somatostatin receptor-positive gastroenteropancreatic neuroendocrine tumors (GEP-NETs). Cancer Res. 2021, 81, 674. [CrossRef]

185. Raymond, L.M.; Korzun, T.; Kardosh, A.; Kolbeck, K.J.; Pommier, R.; Mittra, E.S. The state of peptide receptor radionuclide therapy and its sequencing among current therapeutic options for gastroenteropancreatic neuroendocrine tumors. Neuroendocrinology 2021, 111, 1086-1098. [CrossRef] [PubMed]

186. Lamberti, G.; Faggiano, A.; Brighi, N.; Tafuto, S.; Ibrahim, T.; Brizzi, M.P.; Pusceddu, S.; Albertelli, M.; Massironi, S.; Panzuto, F.; et al. Nonconventional doses of somatostatin analogs in patients with progressing well-differentiated neuroendocrine tumor. $J$. Clin. Endocrinol. Metab. 2020, 105, dgz035. [CrossRef] [PubMed]

187. Faggiano, A.; Di Maio, S.; Mocerino, C.; Ottaviano, M.; De Divitiis, C.; Guarnotta, V.; Dolce, P.; Modica, R.; Puliafito, I.; Tozzi, L.; et al. Therapeutic sequences in patients with grade 1-2 neuroendocrine tumors (NET): An observational multicenter study from the ELIOS group. Endocrine 2019, 66, 417-424. [CrossRef]

188. Ricci, C.; Lamberti, G.; Ingaldi, C.; Mosconi, C.; Pagano, N.; Alberici, L.; Ambrosini, V.; Manuzzi, L.; Monari, F.; Malvi, D.; et al. Treatment of advanced gastro-entero-pancreatic neuro-endocrine tumors: A systematic review and network meta-analysis of phase iii randomized controlled trials. Cancers 2021, 13, 358. [CrossRef]

189. Panzuto, F.; Rinzivillo, M.; Fazio, N.; de Braud, F.; Luppi, G.; Zatelli, M.C.; Lugli, F.; Tomassetti, P.; Riccardi, F.; Nuzzo, C.; et al. Real-world study of everolimus in advanced progressive neuroendocrine tumors. Oncologist 2014, 19, 966-974. [CrossRef]

190. Maggio, I.; Panzuto, F.; Manuzzi, L.; Dall'Olio, V.; Rinzivillo, M.; Campana, D.; Lamberti, G. 1179P Therapeutic sequences in advanced grade 1-2 pancreatic neuroendocriene tumours (PNET). Ann. Oncol. 2020, 31, S780. [CrossRef]

191. Severi, S.; Sansovini, M.; Ianniello, A.; Bodei, L.; Nicolini, S.; Ibrahim, T.; Di Iorio, V.; D’Errico, V.; Caroli, P.; Monti, M.; et al. Feasibility and utility of re-treatment with (177)Lu-DOTATATE in GEP-NENs relapsed after treatment with (90)Y-DOTATOC. Eur. J. Nucl. Med. Mol. Imaging 2015, 42, 1955-1963. [CrossRef] [PubMed] 